Pontifícia Universidade Católica

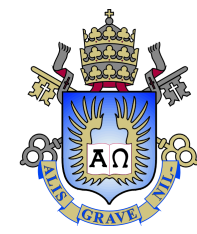

Vinícius de Lima Costa

Uma ferramenta de RV para tratamento de fobia de voar controlada pelo terapeuta

Dissertação apresentada ao Programa de Pós-graduação em Informática da PUC-Rio como requisito parcial para obtenção do grau de Mestre em Informática.

Orientador: Prof. Alberto Barbosa Raposo 
Vinícius de Lima Costa

\title{
Uma ferramenta de RV para tratamento de fobia de voar controlada pelo terapeuta
}

Dissertação apresentada como requisito parcial para obtenção do grau de Mestre pelo Programa de Pós-graduação em Informática da PUC-Rio. Aprovada pela Comissão Examinadora abaixo assinada.

\author{
Prof. Alberto Barbosa Raposo \\ Orientador \\ Departamento de Informática - PUC-Rio \\ Dr. Marcus Franco Costa de Alencar \\ Fundação Pe Leonel Franca - FPLF
}

Prof. Jauvane Calvacante de Oliveira Laboratório Nacional de Computação Científica - LNCC

Prof. Marcio da Silveira Carvalho

Coordenador Setorial do Centro Técnico Científico - PUC-Rio 
Todos os direitos reservados. É proibida a reprodução total ou parcial do trabalho sem autorização da universidade, do autor e do orientador.

\section{Vinícius de Lima Costa}

Graduou-se em Ciência da Computação no Pólo Universitário de Rio das Ostras da Universidade Federal Fluminense (Rio das Ostras, RJ). Durante o mestrado desenvolveu em conjunto com outro aluno de mestrado o simulador de voo e, sozinho, o controlador móvel deste simulador.

Ficha Catalográfica

de Lima Costa, Vinícius

Uma ferramenta de RV para tratamento de fobia de voar controlada pelo terapeuta / Vinícius de Lima Costa; orientador: Alberto Barbosa Raposo. - 2016.

v., 47 f: il. color. ; $30 \mathrm{~cm}$

Dissertação (mestrado) - Pontifícia Universidade Católica do Rio de Janeiro, Departamento de Informática.

Inclui bibliografia

1. Informática - Teses. 2. Computação Gráfica - Teses. 3. Realidade Virtual;. 4. Medo de Voar;. 5. Fobia;. 6. Jogos;. 7. Simulação.. I. Barbosa Raposo, Alberto. II. Pontifícia Universidade Católica do Rio de Janeiro. Departamento de Informática. III. Título. 


\section{Agradecimentos}

Queria agradecer, primeiramente os meus pais. Sem o apoio incondicional deles nada disso seria possível. Nos dias mais claros e nas noites mais densas, eles sempre estiveram presentes. Também gostaria de agradecer os amigos Welton Barbosa e Luiz Guilherme Santos, que me acolheram em Niterói quando eu precisava de um lugar e sempre foram excelentes parceiros desde a faculdade. Agradecimentos em especial a minha atual colega de apartamento, Naone Wagner Lopes, por ser sempre um amor e Helder Martins por ser um cara muito tranquilo. O ultimo amigo que gostaria de agradecer é o Kildare Silveira que se formará em Computação agora e também divide apartamento comigo. Por fim gostaria de agradecer meu orientador Alberto Raposo. A ajuda dele

$\stackrel{\circ}{\sim}$ foi de extrema importância para este trabalho e é um dos melhores professores ن que já tive o prazer de conversar. 


\section{Resumo}

de Lima Costa, Vinícius; Barbosa Raposo, Alberto. Uma ferramenta de RV para tratamento de fobia de voar controlada pelo terapeuta. Rio de Janeiro, 2016. 47p. Dissertação de Mestrado - Departamento de Informática, Pontifícia Universidade Católica do Rio de Janeiro.

O medo de voar é um problema comum nos dias de hoje. Também conhecido como aerofobia ou aviofobia, o medo pode ser definido como "uma fobia específica marcada por um medo excessivo persistente pela experiência ou possibilidade de se viajar através do ar". Diversas pessoas sofrem com esse tipo de fobia, o que faz com que a procura por tratamentos seja alta. O tratamento mais efetivo é o tratamento via exposição in vivo. Porém, este tratamento geralmente é muito caro, já que exige o deslocamento até o aeroporto e a entrada no avião, sendo que o paciente pode acabar nem voando pelo medo. O presente trabalho propõe a criação de um simulador de voo 3D em realidade virtual, com ênfase no ângulo de visão do passageiro. Além deste simulador, uma aplicação de controle em dispositivo móvel foi desenvolvida para que o psiquiatra responsável possa controlar o estado da aplicação e a quantidade de estímulos passada ao paciente sem quebrar a imersão do mesmo no ambiente virtual. A eficiência da realidade virtual em transmitir a sensação de medo para o usuário da aplicação e a eficácia da aplicação móvel foram avaliadas junto a psiquiatras e através de um teste-piloto com um paciente do IPUB/UFRJ, além de uma apresentação a psiquiatras da PUC-Rio.

\section{Palavras-chave}

Realidade Virtual; Medo de Voar; Fobia; Jogos; Simulação. 


\section{Abstract}

de Lima Costa, Vinícius; Barbosa Raposo, Alberto (Advisor). A VR tool for fear of flying treatment controlled by the therapist.. Rio de Janeiro, 2016. 47p. MSc. Dissertation - Departamento de Informática, Pontifícia Universidade Católica do Rio de Janeiro.

The problem known as fear of flying is common nowadays. Also known by other names such as aviophobia or aerophobia, this kind of fear can be defined as " a specific phobia noted by a persistent excessive fear of travelling or possibility of travel through the air". Many people suffer from this kind of phobia, creating a high demand for treatments in this area. The most effective way to treat someone is by in vivo exposition. However, this kind of treatment is usually expensive, since there is a need to go to an airport and to get aboard a plane. At the end, the patient may not even try to go through with the flight because of his/her excessive fear. The present work focuses on creating a 3D virtual reality flight simulator, from the passenger point of view. In addition to this simulator, there is also a mobile application that controls the current state of the main application and the stimulus that can be passed to the patient without interrupting the immersion on the main application. The effectiveness of the virtual reality application in transmitting the sense of fear and the effectiveness of the mobile application were evaluated with the help of psychiatrists from IPUB/UFRJ and a pilot test, plus a presentation to PUC-Rio psychiatrists.

\section{Keywords}

Virtual Reality; Fear Of Flight; Phobia; Games; Simulation. 


\section{Sumário}

$\begin{array}{lll}1 & \text { Introdução } & 10\end{array}$

2 Revisão da Literatura $\quad 12$

2.1 Histórico da Realidade Virtual 12

2.2 Uso de RV para Tratamentos de Fobias em Geral 13

2.3 Uso de RV para tratamento de medo de voar 14

$\begin{array}{lll}2.4 & \text { Adaptação Afetiva } & 16\end{array}$

3 Desenvolvimento $r$

$\begin{array}{lll}3.1 & \text { Recursos Utilizados } & 18\end{array}$

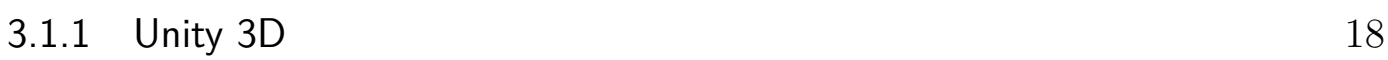

$\begin{array}{lll}3.1 .2 & \text { Oculus Rift } & 20\end{array}$

3.1.3 Fuse 20

3.2 Conceito da Aplicação de RV 21

3.3 Implementação da Aplicação de RV 24

3.4 Desenvolvimento da Aplicação Móvel 27

4 Avaliação $\quad 31$

$\begin{array}{lll}5 & \text { Conclusão e trabalhos futuros } & 37\end{array}$

$\begin{array}{ll}\text { Referências bibliográficas } & 39\end{array}$

$\begin{array}{ll}\text { Apêndices } & 42\end{array}$

A The Spatial Presence Experience Scale Questionnaire 42

B Technology Acceptance Model Extended $\quad 45$ 


\section{Lista de figuras}

2.1 Foto do Sensorama em Ação(06) 12

2.2 Simulador de Movimento Completo(02) 15

2.3 Controle demasiado complexo de aplicação (13) 16

3.1 Captura de tela da aplicação de RV em desenvolvimento dentro do Unity 19

3.2 Diagrama de Execução da Aplicação 22

3.3 Corredor de Embarque do Avião 22

$\begin{array}{ll}3.4 & \text { Interior do Avião } \\ 3.5 & 23\end{array}$

3.5 Avião em processo de decolagem 23

3.6 Tela da Aplicação Móvel 24

3.7 Diagrama de Fluxo da execução de métodos dentro do Unity (19) 25 


\section{Lista de tabelas}

4.1 Descrição de cada sessão no tratamento - Ideia Inicial e Protocolo Executado 


\section{Introdução}

O medo de voar é um problema comum nos dias de hoje. Também conhecido como aerofobia ou aviofobia, o medo é definido como "uma fobia específica marcada por um medo excessivo persistente pela experiência ou possibilidade de se viajar através do ar"(01).

Segundo estudos(02), um a cada seis adultos tem medo de voar e 3-5\% do público não usaria este meio de transporte. A maioria das pessoas com medo é do sexo feminino(02).

Em um relatório redigido pela empresa Depla, 38-44\% das pessoas com medo de voar sofreram com problemas graves nas suas vidas, além de terem suas escolhas de carreira e trabalho limitadas pelo medo de voar. Por fim, o medo pode vir acompanhado por sensações de vergonha ou estresse aguçado, piorando assim o dia a dia da pessoa que sofre desta fobia(02).

Por conta disso, a fobia de avião é uma área bastante explorada por psiquiatras para se encontrar tratamentos eficazes. Existem tratamentos diversos como dessensibilização sistemática , treinamento de relaxamento, preparação cognitiva e automotivação, inundação, implosão e exposição in vivo (03).

O tratamento que se prova mais efetivo atualmente é a exposição in vivo. Entretanto, já foi comprovado que o tratamento em realidade virtual (RV) pode ser tão eficaz quanto a exposição in vivo(04). Por outro lado, a maioria dos tratamentos baseados em RV existentes até bem pouco tempo usavam HMDs (Head Mounted Displays)de custo alto e difícil acesso ao usuário final.

Com a recente proliferação de dispositivos de realidade virtual, incluindo HMDs como o Oculus Rift(05) e o Gear VR(28), a tecnologia como um todo está muito mais acessível ao público em geral. Portanto, atualmente é muito mais simples para pesquisadores, desenvolvedores e terapeutas conseguirem os equipamentos necessários para conseguir usar a realidade virtual.

Porém, uma ferramenta de RV também pode ser limitada, se ela simplesmente se limitar a um roteiro pré-concebido de situações, por exemplo, uma simulação onde o o clima está sempre aberto e sempre se passa no período da manhã. É interessante ter algo que possibilite a manipulação do estado desta simulação. Aqui, é apresentada uma aplicação móvel que permite tal manipulação. A ideia surgiu da parceria com o grupo do Laboratório Integrado de 
Pesquisa do Estresse (LINPES), do Instituto de Psiquiatria da UFRJ (IPUB).

Em um primeiro momento, foi concebido o conceito de um tratamento de fobias usando RV como uma espécie de "filme", onde o passageiro/paciente vivenciaria situações pré-definidas. Isso porque, tradicionalmente, a exposição do paciente às situações causadoras da fobia é feita por meio de filmes, áudios, etc. No entanto, à medida que as potencialidades da tecnologia lhes eram apresentadas, ficou claro que a "customização" e controle das situações apresentadas pode ser bastante importante. Isso porque pacientes diferentes reagem de formas diferentes ao tratamento/exposição, de modo que um "poder de controle" dado ao terapeuta pode tornar o tratamento mais adequado a cada paciente, por exemplo, aumentando o nível de estresse para pacientes que reagem bem, ou vice-versa.

Esta dissertação tem como objetivo apresentar o desenvolvimento de um simulador de voo usando a engine Unity incluindo HMDs como o Oculus Rift, complementando-os com uma aplicação de controle para o simulador de voo, que rode em um dispositivo móvel. Ou seja, a aplicação aqui desenvolvida é uma aplicação onde o/a psiquiatra pode controlar o andamento da simulação via a ativação/desativação de estímulos e objetos na simulação ativa ou pela passagem de parâmetros de inicialização.

No decorrer deste texto, o capítulo 2 apresentará uma revisão da literatura e do avanço da realidade virtual conforme a passagem dos anos. No capítulo 3 será apresentado o desenvolvimento das duas aplicações, tanto a de RV quanto a móvel e algumas de suas peculiaridades de parte de código e fluxo de execução. O capítulo 4 apresentará as avaliações feitas do software. A primeira foi feita pela participante do teste piloto, usando a Escala de Experiência de Presença Espacial (The Spatial Presence Experience Scale $(S P E S)$ ), uma escala indicada para se avaliar o quão presente uma pessoa se sente dentro de uma experiência, sendo a experiência deste trabalho uma aplicação de realidade virtual. Também foi feita uma análise de quão útil pode ser o software por psiquiatras da PUC-Rio que não estavam envolvidos com o processo de criação da aplicação usando o Modelo de Aceitação de Tecnologia Estendido (Technology Acceptance Model Extended (TAM)). Por fim, também foi pedido um feedback da psiquiatra do IPUB/UFRJ presente na sessão de teste piloto.

Por fim, o capítulo 5 trará a conclusão e os trabalhos futuros que podem ser construídos em cima do desenvolvimento desta dissertação. 


\section{2}

\section{Revisão da Literatura}

Neste capítulo são apresentados o histórico da realidade virtual, mostrando a evolução da ideia desde sua concepção até os dias de hoje além de artigos e trabalhos relacionados ao apresentado aqui, mostrando outras ideias de como como tratar fobias, e em particular o medo de voar, via realidade virtual.

\section{1}

\section{Histórico da Realidade Virtual}

Embora pareça novidade, a realidade virtual já é um conceito antigo, se formos levar em consideração a sua origem. Este conceito foi introduzido pela primeira vez na coletânea de ensaios "Le Théâtre et son double", publicada em 1938 pelo autor Antonin Artaud, como um puro conceito de ficção cientifica.

A realidade virtual, como conceito que realmente existe, é de interesse geral desde os anos 50, com o Sensorama(06)(Figura 2.1), uma máquina que permitia a interação de um usuário com filmes curtos através do tato, visão, olfato e audição. Já o primeiro conceito de Head Mounted Display que nos trouxe mais próximo aos dias de hoje foi criado por Ivan Sutherland e seu aluno Bob Sproull em 1966(07). Era um dispositivo primitivo, em que todos os gráficos eram feitos por wireframes.

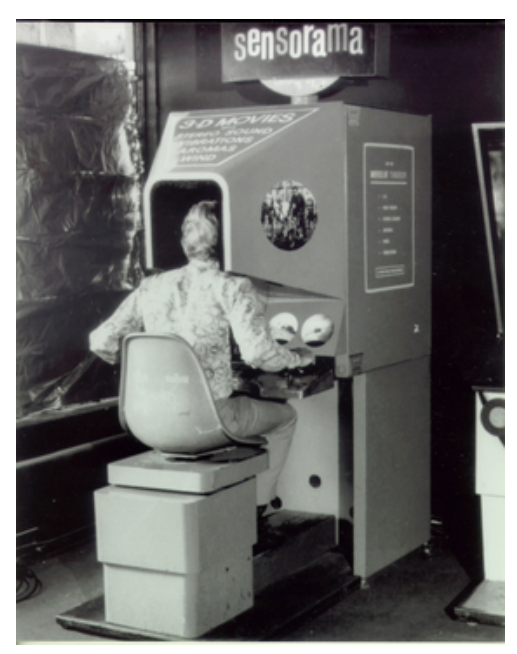

Figura 2.1: Foto do Sensorama em Ação(06) 
Mesmo sendo uma ideia antiga, só recentemente com o Oculus Rift(05) é que a tecnologia de realidade virtual começou a ser comercializado como um produto para o consumidor comum. O Oculus foi criado a partir de um financiamento coletivo que rendeu \$2.437.429 dólares em Setembro de 2012. A partir de Março de 2013, desenvolvedores já podiam comprar versões de desenvolvedor do equipamento e, em 28 de Março de 2016, o dispositivo de realidade virtual começou a ser finalmente vendido para as massas.

O sucesso do crowndfunding e expectativa em geral em torno do Oculus fez com que diversas outras empresas começassem a desenvolver seus próprios óculos de realidade virtual, como o HTC Vive (desenvolvido em parceria pela Valve e HTC) e o Playstation $V R$ (desenvolvido pela Sony com foco na plataforma Playstation 4). Também existem alternativas baratas para uma realidade virtual menos imersiva em smartphones como o Google Cardboard, feito inteiramente de papelão e duas lentes e o Gear $V R$, uma capa de plástica com lentes para se colocar o smartphone dentro e usar o conjunto como dispositivo de realidade virtual.

\section{2}

\section{Uso de RV para Tratamentos de Fobias em Geral}

A realidade virtual já é usada no tratamento de fobias diversas, como, por exemplo a de aranhas(09), claustrofobia(10) e acrofobia(medo de altura)(11). Em todos esses casos, o tratamento em realidade virtual trouxe um ganho para o paciente, reduzindo seu grau de ansiedade com a fobia especificada de uma maneira mais segura para o paciente do que a exposição in vivo.

Carlin e Suzanne(09) apresentaram um sistema de RV para tratamento de fobia de aranhas onde os pacientes entravam dentro de uma cozinha virtual onde uma aranha virtual se aproximava de maneira devagar do usuário. O objetivo final era conseguir segurar a aranha com a "mão" dentro do mundo virtual.

Botella et al.(10), desenvolveram um sistema para tratamento de claustrofobia onde o paciente interagia com os seguintes diferentes espaços virtuais.

- Uma varanda ou pequeno jardim de $2 x 5 \mathrm{~m}^{2}$

- Uma sala de $4 x 5 m^{2}$ com conexão à varanda e uma grande janela que podia ser aberta.

- Uma sala de $3 x 3 m^{2}$ que se conectava as anteriores. Esta sala não tinha móveis ou janelas e seu teto e piso eram mais escuros, para dar uma sensação maior de se estar em um espaço fechado. Além disso, existia uma parede dentro desta sala que podia se aproximar ou afastar pelo desejo do paciente. 
Para o tratamento de acrofobia, Rothbaum et al.(11) desenvolveram um sistema onde o paciente entrava em um elevador panorâmico que continha três botões: para cima, para baixo e parar. O paciente era encorajado a ficar em cada andar o máximo que podia.

\section{3}

\section{Uso de RV para tratamento de medo de voar}

Já existem alguns trabalhos que relacionam a realidade virtual com o medo de voar. Um destes foi feito em 2002(12). A simulação contava com uma máquina usando um Intel Pentium III, 450-MHz, 128-Mb RAM, placa de vídeo Riva TNT2 com 64Mb de RAM, rodando Windows NT/2000, usando HMDs da empresa I/O. A simulação continha três cenários distintos:

- Quarto em Casa: Um cenário de planejamento, numa sala que recria o momento de arrumar as malas para o voo. É basicamente um quarto, aonde o terapeuta tem controle sobre o tempo e clima do lado de fora. Além disso, há um rádio que pode passar "notícias", que são mensagens especificadas pelo terapeuta.

- Dentro do Aeroporto: Este cenário já deixa o paciente dentro do aeroporto, no salão de embarque. Neste cenário, a única coisa que ele pode fazer é se movimentar pelo aeroporto, de maneira livre. Além disso, o terapeuta pode mudar informações sobre voos chegando e mensagens do viva-voz.

- Dentro do Avião: Nesta ultima cena, o paciente fica preso a cadeira do avião enquanto este faz a viagem. Aqui o avião passa pelas etapas de partida, viagem e pouso.

Esse trabalho(12), inspirou as fases da ferramenta de RV desenvolvida na presente dissertação. Aqui, foram consideradas as duas últimas fases: saguão do aeroporto e avião. Também observa-se que a aplicação de 2002 já dava algum controle ao terapeuta, de forma totalmente offline, sem ser em tempo de execução.

Já um outro estudo, também de 2002, fazia a comparação entre o tratamento in vivo e um tratamento em realidade virtual(04). O teste foi feito com pessoas com medo de altura. Após um pré-teste, cada paciente era aleatoriamente escolhido para ser tratado via RV ou via a exposição in vivo. Como resultado, se teve que o tratamento via realidade virtual era tão efetivo quanto a exposição, com base nos indicadores do AQ(Acrophobia Questi- 
onnaire), ATHQ(Attitude Towards Heights Questionnaire) e BAT(Behavioral Avoidance Test).

Em 2013, um trabalho para tratamento de fobia de avião(02) foi feito com o uso de um Full Motion Simulator(FMS), um hardware de simulação de voo completo capaz de inclinar-se, guinar, fazer movimentos longitudinais e até mesmo aplicar força-G e efeitos de turbulência no usuário (Figura 2.2 ). Por conta disso, essa é a simulação mais próxima da realidade sem os riscos desta. Porém, também é a mais cara já que esse tipo de hardware não se acha no atacado ou varejo e é vendido apenas por encomenda.

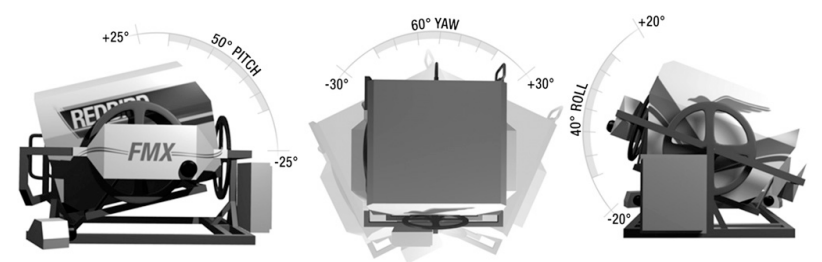

Figura 2.2: Simulador de Movimento Completo(02)

O tratamento com um FMS se prova eficiente não só para pessoas com medo de voar mas também para pessoas que tem fobias que podem se manifestar durante um processo de voo, como medo de altura(02). Dado que a simulação é o mais próximo da realidade, um primeiro pensamento é de que este é o tratamento mais eficaz na área mas ainda faltam estudos de comparação para comprovar a eficácia deste método comparado à outros.

Em 2009, um estudo combinou a ideia de se ter a simulação de RV com um controle para o terapeuta poder usar(13). O dispositivo RV usado era o VRET, da Universidade de Felt. Porém, o controle desenvolvido era demasiadamente complexo, já que envolvia, além de variáveis como clima e tempo, o controle do próprio avião e o timing de todas as ações como quando passar a mensagem de decolagem ou de aterrissagem (Figura 2.3).

Embora os pacientes se sentissem imersos na experiência virtual, a complexidade apresentada nos comandos possíveis dentro do controle faziam com que os psiquiatras acabassem errando no andamento da aplicação como, por exemplo, tocar uma mensagem em um momento que não deveria ou abrir as portas antes do avião ter completamente pousado. Mesmo assim, estes erros aparentemente não tiveram efeitos negativos na experiência como um todo.

Um estudo mais recente, de 2014(14), também usa a realidade virtual relacionada ao voo mas neste caso para a preparação de treinamentos para fuga de emergência em caso de acidente.

Como se pode perceber, já existem diversos trabalhos na área. Porém, estes trabalhos acabam tendo aplicação limitada pelo seu uso de HMDs ou 


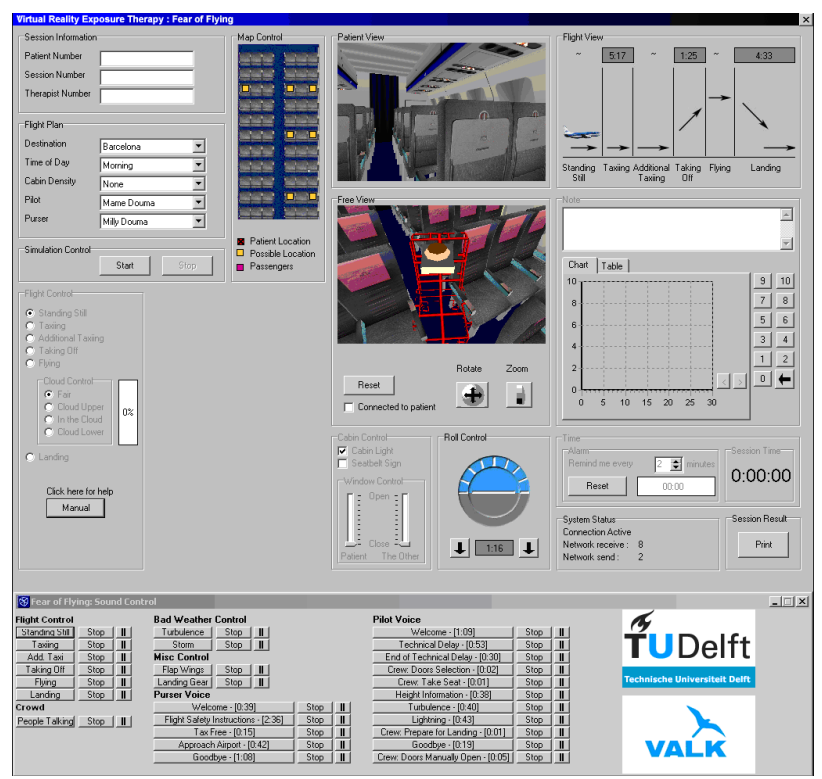

Figura 2.3: Controle demasiado complexo de aplicação (13)

outros dispositivos muito caros. Porém, aqui neste trabalho, o foco é feito com um dispositivo que, neste momento, já está a venda no mercado internacional para o usuário final.

Além disso, com exceção de um trabalho(13), nenhum deles permite que o psiquiatra controle o estado da aplicação enquanto ela está rodando. E mesmo assim, naquela em que o controle é permitido, é um processo complicado já que exige conhecimentos específicos sobre o voo de aviões, que não são familiares ao terapeuta. Portanto, ter um controle remoto para mudanças de estado da aplicação em tempo de execução é um diferencial importante da aplicação aqui desenvolvida, e que caminha na direção da adaptação afetiva de aplicações.

2.4

\section{Adaptação Afetiva}

A realidade virtual tem diversas vantagens em comparação ao tratamento tradicional in vivo em termos de acessibilidade e custos. Como é dito na referência (04), a realidade virtual pode ser tão eficiente quanto a exposição in vivo. Além disso, o tratamento in vivo(25) pode trazer riscos a saúde do paciente, além de constrangimento publico que podem deixar o paciente desconfortável, fazendo com que ele possa recusar o tratamento por causa destes fatores. Certos estudos indicam que os pacientes se mostram mais dispostos à exposição em RV do que in vivo(26).

Porém, para o psiquiatra, pode criar uma situação complicada já que ele fica responsável por monitorar o estado físico e mental do paciente além da aplicação em si. Como mostrado no trabalho(13), erros podem acabar sendo 
cometidos por uma falta de familiaridade com o sistema. O ideal seria ter um sistema que se adaptasse conforme os sinais de ansiedade do paciente como batimentos cardíacos, suor, mãos tremulas ou atividades cerebrais específicas. Além disso, a comunicação do psiquiatra com o paciente acaba quebrando o sentimento de presença do paciente na aplicação, já que é uma interferência externa que não vem diretamente da aplicação. Quanto maior o sentimento de presença, melhor é o resultado do tratamento(27).

O trabalho aqui desenvolvido não consegue se adaptar automaticamente a situação do paciente através de suas características físicas e fisiológicas porque isso exigiria equipamentos específicos para leituras dos seus sinais vitais, bem como um entendimento aprofundado da relação entre a variação desses sinais vitais e as adaptações necessárias no ambiente virtual. Além disso, isto extrapola o escopo do presente trabalho. Então a ideia foi simplificar o controle remoto o máximo possível para que o psiquiatra possa se focar mais no paciente. 


\section{Desenvolvimento}

\section{1}

\section{Recursos Utilizados}

\subsection{1}

Unity 3D

A engine Unity (Figura 3.1) é uma engine voltada para a criação de jogos criada pela empresa Unity Technologies. No início, foi anunciada somente com suporte para o Mac OS X, na Apple's Worldwide Developers Conference de 2005 .

Hoje em dia a engine pode ser usada, como desenvolvedor, no Windows e no Mac OSX. Além disso, é possível criar aplicações dentro dela para as seguintes plataformas:

- Android

- Apple TV

- BlackBerry 10

$-\mathrm{iOS}$

- Linux

- Nitendo 3DS e outros aparelhos da mesma família

- OS X

- Playstation 3

- Playstation 4

- Playstation Vita

- Unity Web Player para o uso em páginas web

- Wii

- Wii U

- Windows 8 Phone

- Windows

- Xbox 360 
- Xbox One

Além disso, o Unity é o SDK padrão para desenvolvimento de jogos para download da plataforma Wii U (15) da Nintendo.

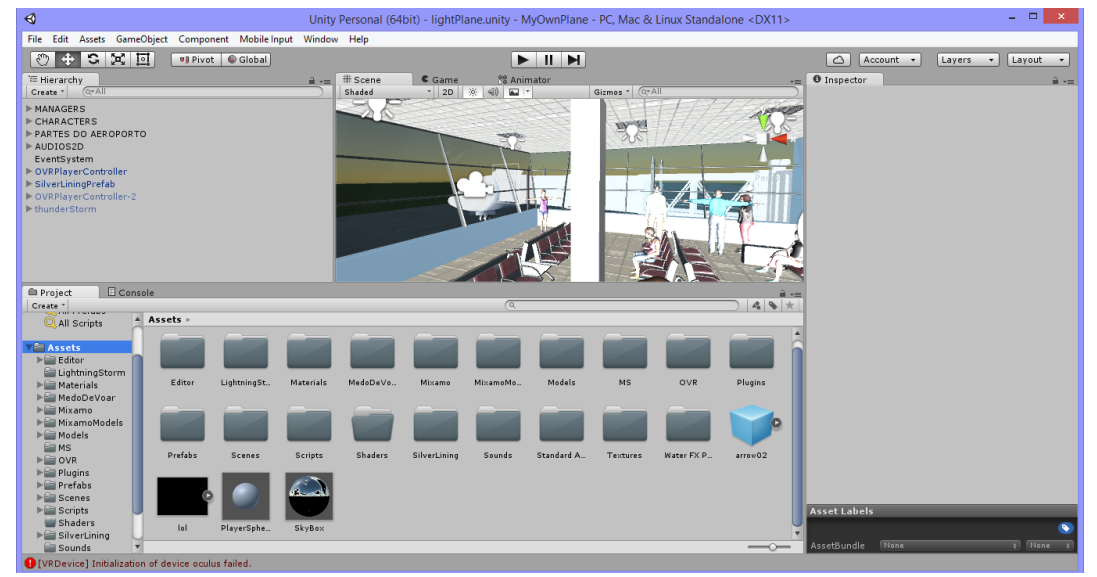

Figura 3.1: Captura de tela da aplicação de RV em desenvolvimento dentro do Unity

A grande vantagem do uso desta engine em cima de outras mais tradicionais é a facilidade de prototipação já que ela possuí diversos assets(objetos de jogo) pré prontos ou modularizados. Diversos jogos de sucesso já usaram a engine, sejam eles independentes ou não. Alguns exemplos incluem:

- Guns Of Icarus Online (Muse Games - Mac OS X, Windows, Linux e Playstation 4)

- The World Ends With You-Solo Remix (Square-Enix - iOS)

- Angry Birds 2 (Rovio - Android e iOS)

- Cuphead (StudioMDHR - Xbox One e PC)

- Corpse Party 2: Dead Patient(GrindHouse - Windows)

A engine Unity foi escolhida justamente por seu extenso uso na área de jogos e sua facilidade de prototipação. Com esta facilidade, o processo de testes de cada adição na aplicação fica bem simples, permitindo que o desenvolvedor crie a aplicação de uma maneira incremental, fazendo o avanço na aplicação ficar aparente até para não usuários. 


\subsection{2}

\section{Oculus Rift}

O Oculus Rift é um headset de RV feito pela empresa Oculus VR. A empresa nasceu através de uma iniciativa de crowdfunding no site Kickstater(16). Nesta campanha, a empresa conseguiu 2.5 milhões de dólares para começar o desenvolvimento da versão de desenvolvedor.

O primeiro modelo, chamado de Development Kit 1 foi vendido diretamente pela Oculus VR de Setembro de 2012 até Março de 2014. O DK1 tem uma tela de 7 polegadas com resolução de 1280x800 pixels. Por conta da resolução, as imagens geralmente podem aparecer borradas se vistas de um ângulo não adequado.

O segundo modelo disponível, chamado de Development Kit 2 foi lançado em 2014. Este modelo já usava duas telas de OLED com resolução 960x1080 para cada olho, uma taxa de atualização maior e tracking de posição com o auxilio de uma câmera. Estas melhoras no modelo fizeram com que o DK2 ganhasse mais tração no mercado. Em feveiro de 2015, a Oculus VR anunciou que mais de 100.000 unidades do DK2 tinham sido vendidos(17). Este foi o modelo usado no desenvolvimento desta dissertação.

Finalmente, no dia 25 de Março de 2016, a Oculus VR começou a vender a versão do dispositivo para consumo geral. Este hardware tem áudio integrado, tracking de posição em 360 graus e as telas para cada olho tem taxa de atualização em $90 \mathrm{~Hz}$. Além disso, foi dado um maior foco a ergonomia e estética do produto, já que este é voltado para o consumidor final. Dado o recente lançamento do dispositivo, não foi possível testá-lo na aplicação desenvolvida.

\subsection{3}

Fuse

Dentro da aplicação existem diversos avatares no ambiente do jogo, para dar uma sensação maior de realismo ao usuário. Estes avatares estão espalhados pelo saguão do aeroporto virtual e dentro do avião. Os avatares foram criados com a ajuda de um software externo, o Fuse(18). Este programa, da empresa Mixamo, permite que se monte diversos avatares humanos através de combinações pré-definidas de partes do corpo humano (cabeça, pés, torso, mãos), roupas e características faciais (como barba). Após a sua montagem, é possível fazer o upload deste avatar para o site da Mixamo e inserir animações pré-definidas como caminhada ou sentar. Este software foi essencial na construção de cada um dos avatares de uma maneira simples e contínua, sem quebra da imersão. 


\section{2}

\section{Conceito da Aplicação de RV}

Antes de decidir como fazer a simulação em realidade virtual, os psiquiatras do IPUB/UFRJ foram consultados para se ter uma ideia do que seria interessante inserir nesta simulação. Numa primeira ideia, teríamos três simulações diferentes: uma dentro da casa do paciente, outra no aeroporto e, por fim, uma dentro do avião, como sugerido em (12). Porém, a fase ainda na casa do paciente foi descartada para a criação de uma aplicação mais contínua, com tudo dentro de uma aplicação só para evitar quebra de imersão com a mudança de aplicações.

A simulação já começa dentro do aeroporto, cortando a parte de sair de casa. A aplicação é continua: do aeroporto, o usuário pode caminhar para dentro do avião, começar o voo e terminá-lo. Ou seja, nesta implementação, os estágios da aplicação (sala de espera e voo) não estão separados, permitindo uma maior imersão nela.

Podemos dizer que os estágios possíveis da aplicação são aqueles mostrados na Figura 3.2.

Na Sala de Espera, diversos avatares ficam em posições em pé ou sentados. O usuário da aplicação pode ver o avião por uma janela de fora e andar livremente pelo cenário. Quando se sentir preparado, pode caminhar livremente para o avião, através de um corredor de embarque (Figura 3.3) conectado a sala. Dentro do avião, o usuário pode andar pelo avião (Figura 3.4) até decidir se sentar na sua cadeira designada.

Ao sentar na cadeira, o processo de decolagem é apresentado. Primeiramente, o vídeo de avisos sobre o avião começa a tocar. Após disso, o avião passa pelas seguintes etapas:

- Pullback: Nesta etapa, o avião dá ré para poder se desconectar do corredor de embarque

- Taxiout: Aqui o avião ajusta sua rotação, enquanto ainda dá ré para poder se posicionar corretamente na pista para decolar.

- Ascensão (Climb): O avião começa a ganhar velocidade para começar a ascender. (Figura 3.5). Após atingir a velocidade, ele entra em ascensão e continua a subir até a altura desejada para começar o voo de cruzeiro.

- Voo de Cruzeiro (Cruise): Aqui o avião ajusta sua rotação para ficar reto em relação ao horizonte e então voa sem mais alterações na sua rotação e inclinação. Assim ele segue, em direção reta. 


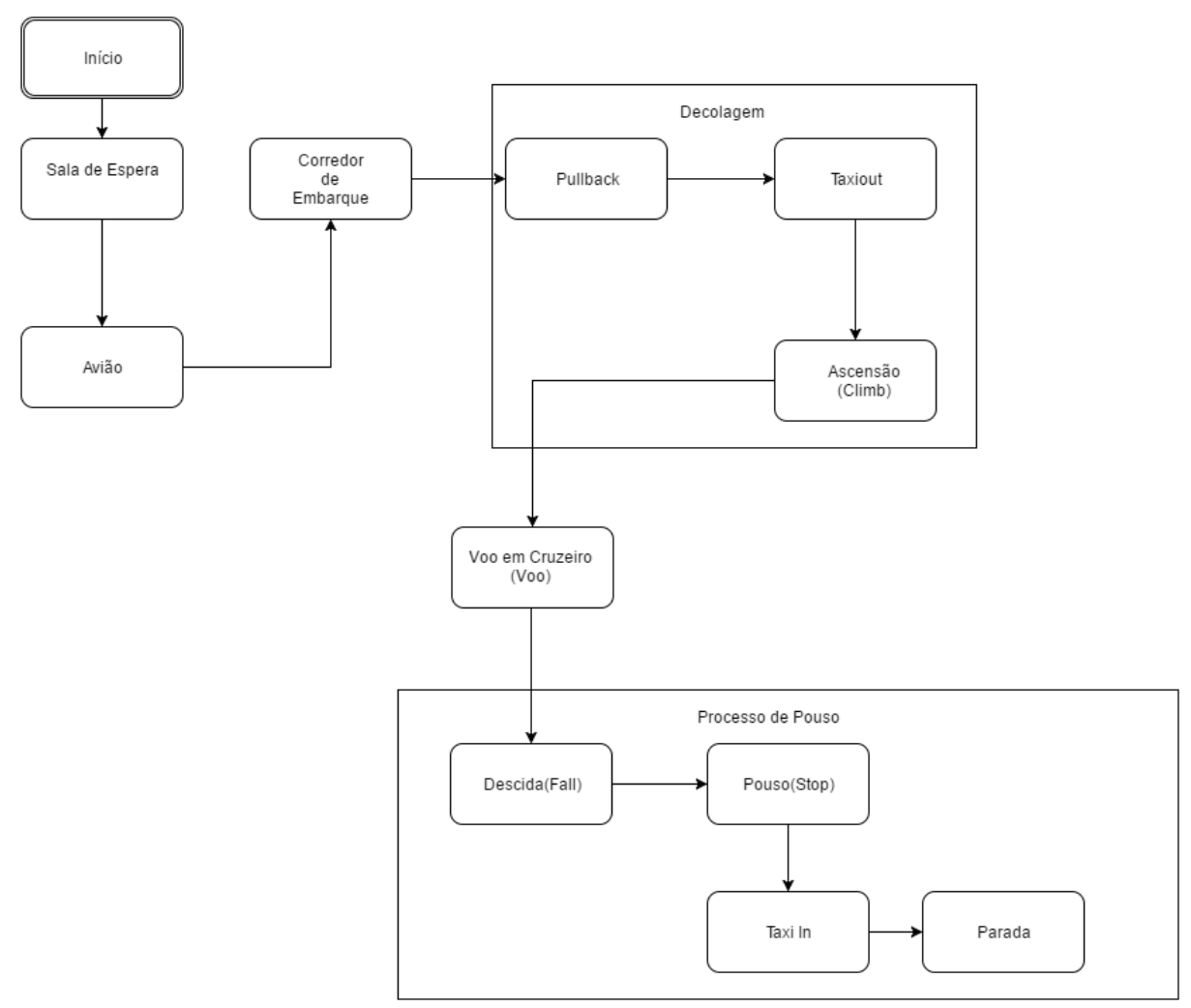

Figura 3.2: Diagrama de Execução da Aplicação

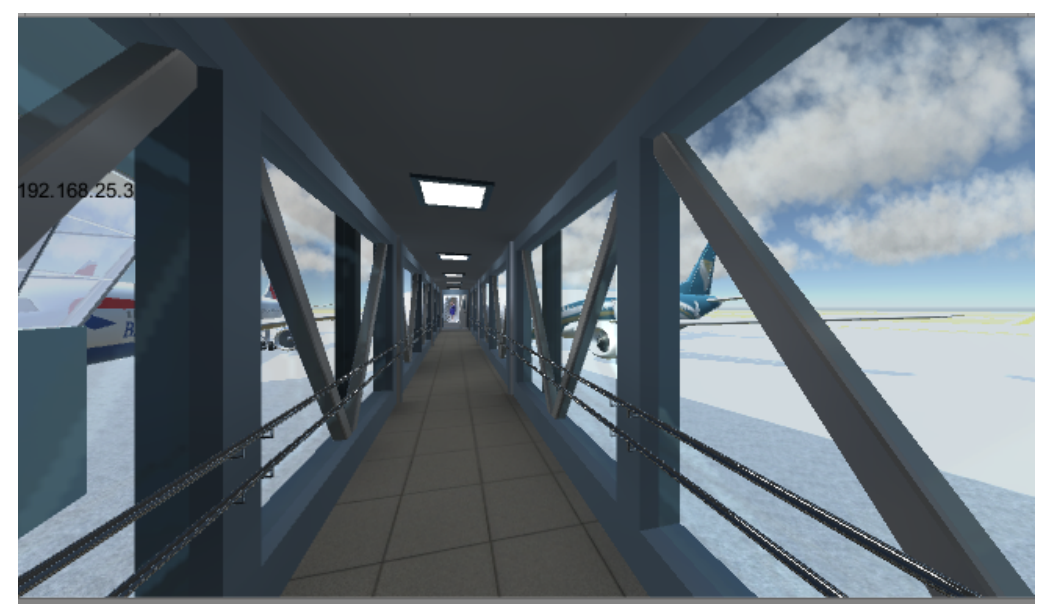

Figura 3.3: Corredor de Embarque do Avião

Depois de o avião atingir o modo de cruzeiro, em qualquer momento da aplicação, o psiquiatra pode inicia a descida ( fall $)$ do avião. Quando o avião chegar ao chão, ele entra em estado de repouso (pouso (stop)). O usuário pode novamente andar livremente e então sair para a sala de espera da chegada, encerrando assim a simulação. Na verdade, ainda existem mais dois estados: Taxi In, para fazer com que o avião se coloque na posição correta para abrir a porta na posição correta para o corredor de desembarque e a parada, fazendo com que o voo termine. No caso da aplicação de RV, o avião 
já pousa de maneira que já fique alinhado com o corredor de embarque e para instantaneamente, simplificando o desenvolvimento e pulando estes dois últimos passos.

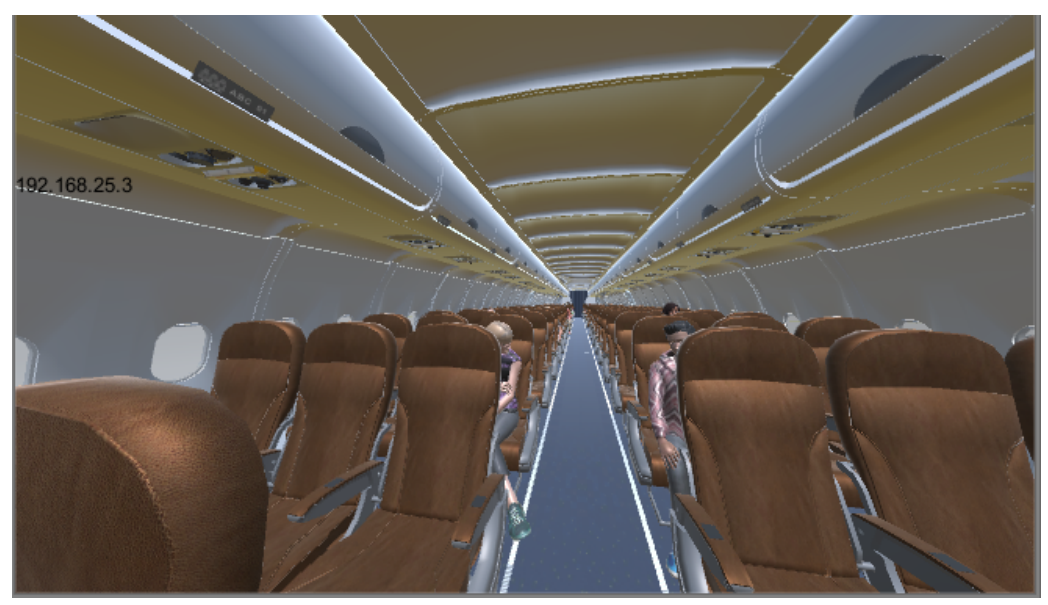

Figura 3.4: Interior do Avião

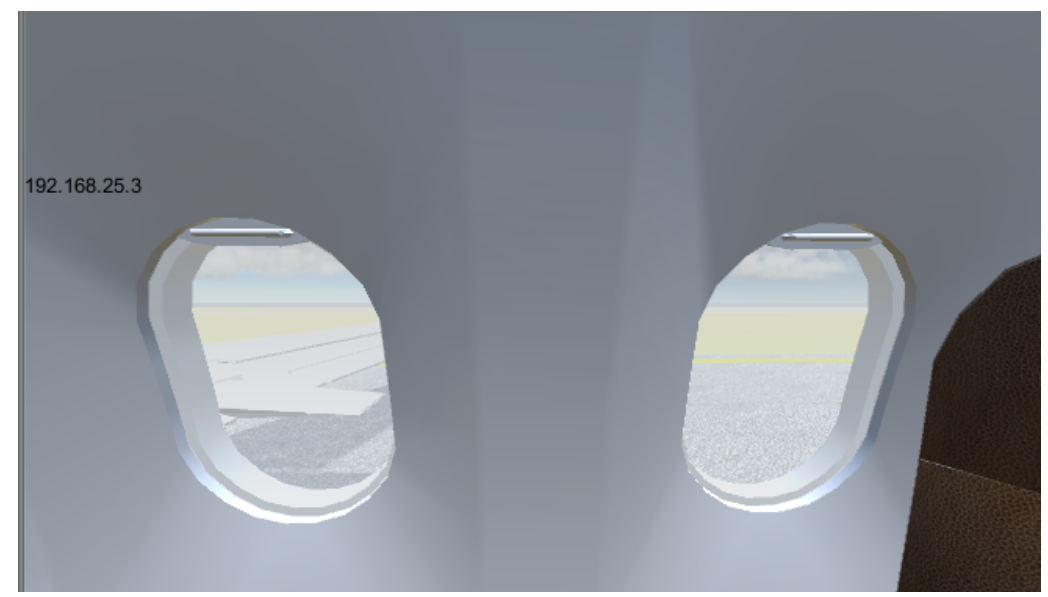

Figura 3.5: Avião em processo de decolagem

Em qualquer momento da aplicação, o psiquiatra também pode mudar a hora atual do dia e\ou o clima (ou seja,se está chovendo, tempo limpo ou nublado). Além disso, ele também pode ativar uma turbulência no avião quando ele estiver em modo de cruzeiro através da aplicação móvel(Figura $3.6)$.

A maior diferença dessa aplicação para outras similares, em questão da sua execução, é portanto ter todo o cenário em um conjunto sem ter que mudar de aplicação durante o tratamento , evitando perda de imersão, e também o controle que é dado ao terapeuta sobre diversos elementos da simulação em andamento. 


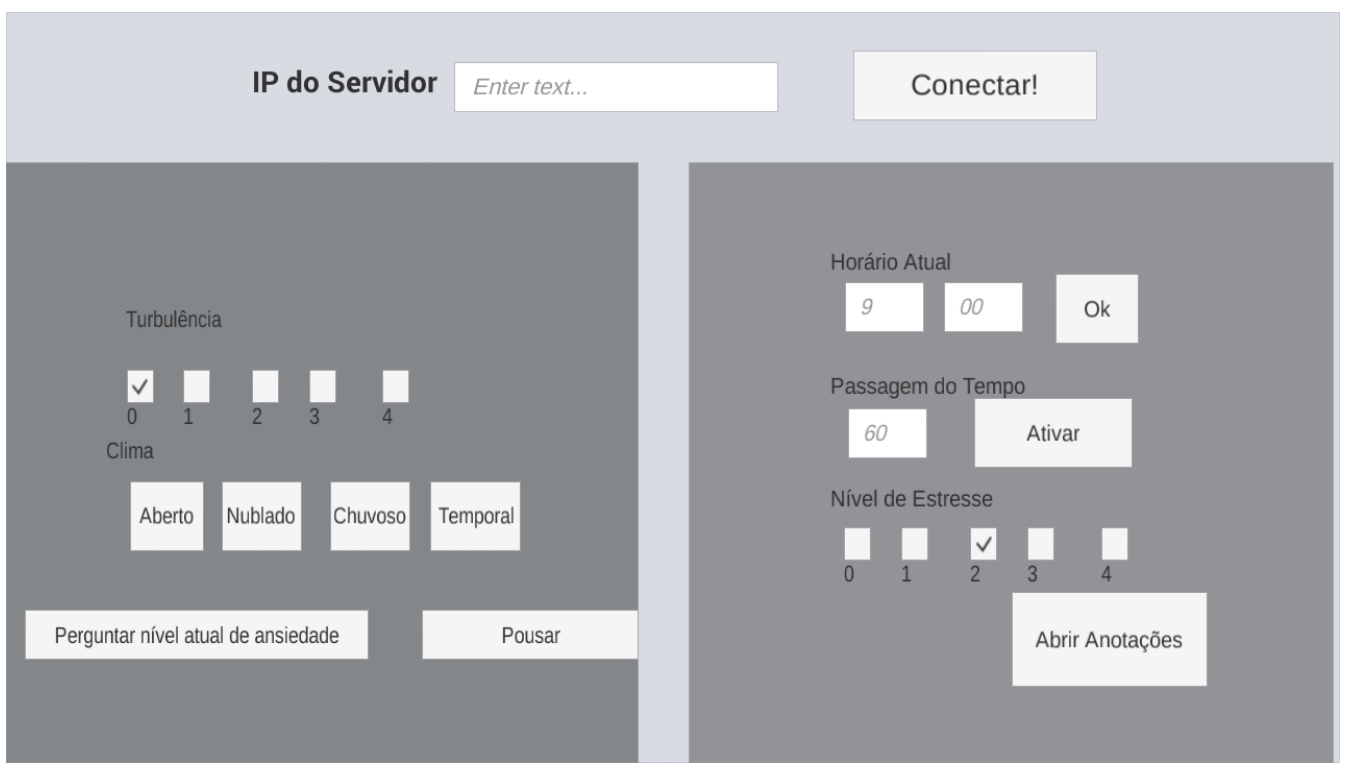

Figura 3.6: Tela da Aplicação Móvel

\section{3}

\section{Implementação da Aplicação de RV}

Para a implementação da aplicação, foram usados um Oculus Rift DK2, Unity 5.3 e computadores com placas de vídeo dedicadas da NVIDIA (GTX 970). Dentro do Unity são usados scripts que foram escritos na linguagem C\#.

O Unity funciona primariamente por scripts, ou seja, códigos que são executados em tempo de execução. Toda classe que deve ser executada dentro do jogo tem que herdar da classe-pai MonoBehaviour que define e controla como e quando as ações vão ocorrer na aplicação corrente. Esses scripts então são ligados a objetos que estarão ativos na aplicação.

Dentro de MonoBehaviour, temos os seguintes métodos que são usados frequentemente:

- Start(): Este método é executado quando o script é carregado na aplicação corrente. É útil para a inicialização de objetos e variáveis.

- Update(): Este método é chamado a cada atualização de frame na aplicação corrente. Ou seja, é dentro dele que ficam as ações que devem acontecer constantemente. Por exemplo, o movimento de um personagem deve ser feito dentro deste método.

- OnDestroy(): Chamado quando o objeto está para ser destruído. Útil para, por exemplo, repassar a mensagem de destruição pra outros objetos que dependiam deste. 


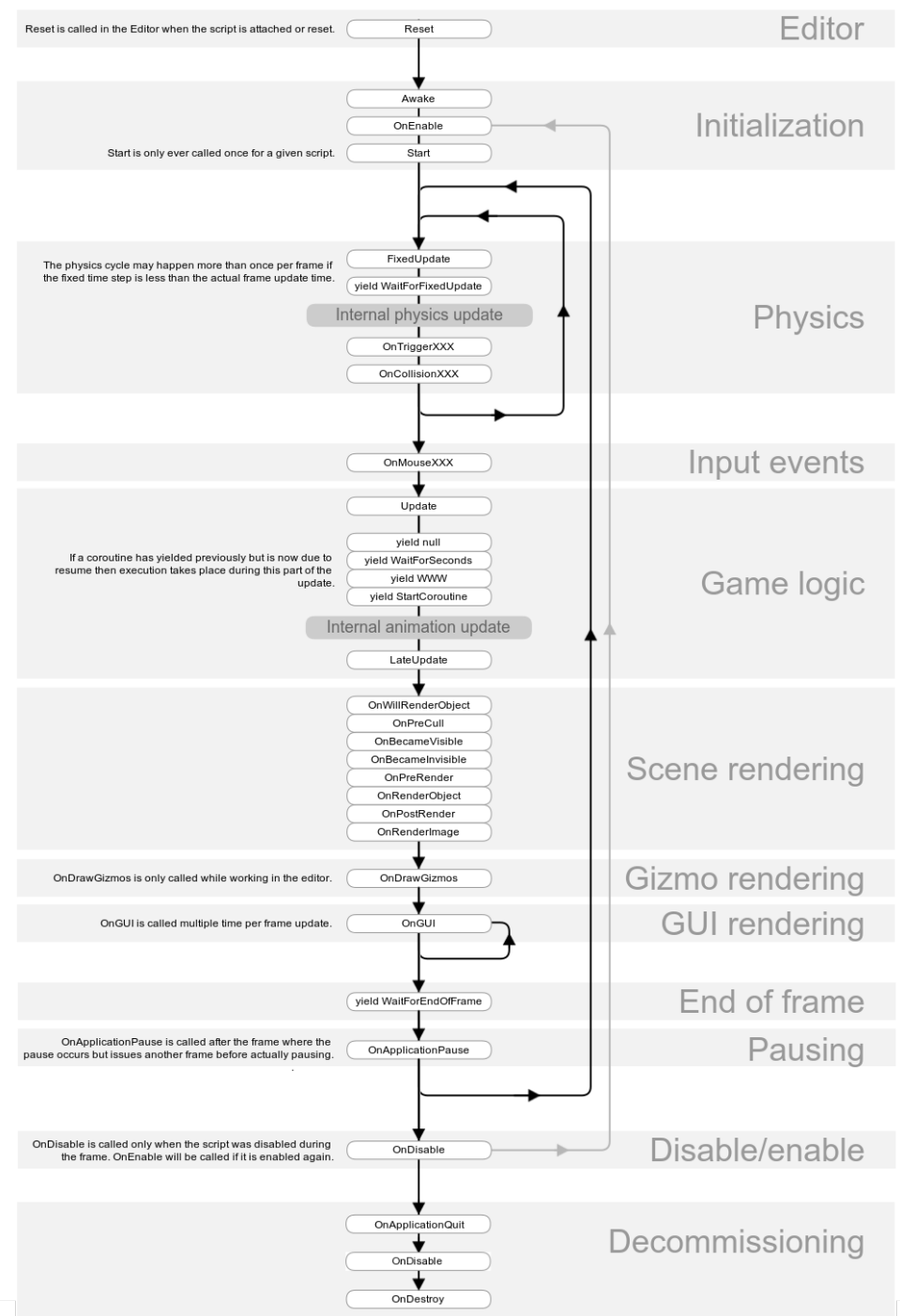

Figura 3.7: Diagrama de Fluxo da execução de métodos dentro do Unity (19)

Estes métodos são chamados em momentos específicos dentro do chamado game loop. Esta é uma estrutura de repetição eterna, que existe dentro dá propria engine, implementada dentro da classe MonoBehaviour. A figura 3.7 demonstra a ordem de execução de todos os métodos pré-determinados possíveis dentro de MonoBehaviour.

Para o comportamento do avião foi feito um script que segue a ideia uma máquina de estados. Estes estados replicam os referidos na figura 3.2, a partir do momento que se está dentro do estado Avião, já que anteriormente, no estado Sala de Espera se tem uma navegação livre, que não exige nenhum controle específico e é basicamente só o movimento do paciente dentro do ambiente da sala de espera. Para se atingir este comportamento foi usado um enumerador para servir de índice do estado corrente. Ao entrar em um estado, após a sua execução, o valor do enumerador então tinha seu valor mudado e 
assim seguia para o próximo estado. Para se melhor entender a ideia, parte do código é apresentada.

Código 3.1: Parte do código que controla o movimento do Avião

public enum PlaneStates \{ pullback, taxiout, climb, cruise, fall, stop \}; PlaneStates currentState;

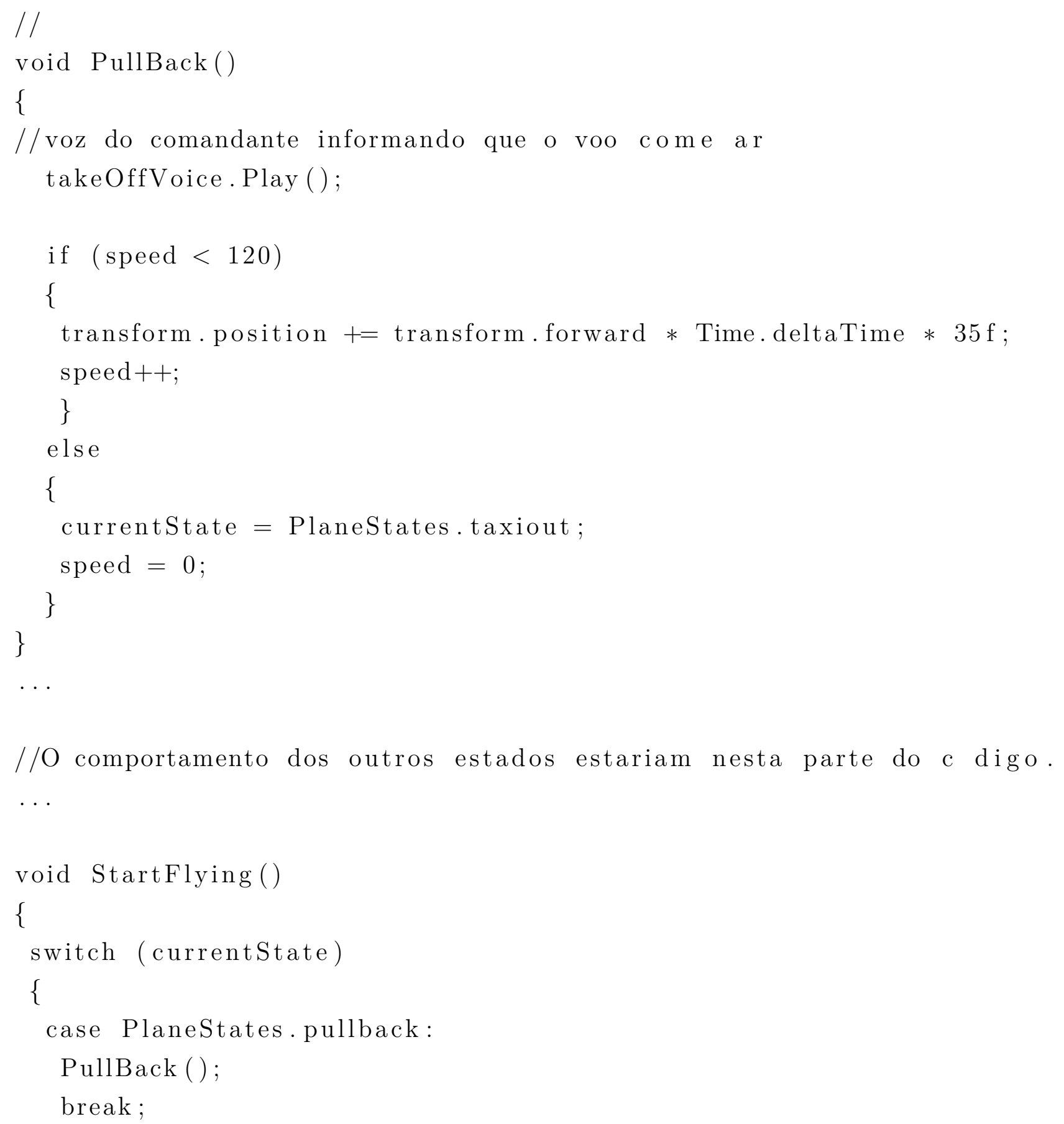




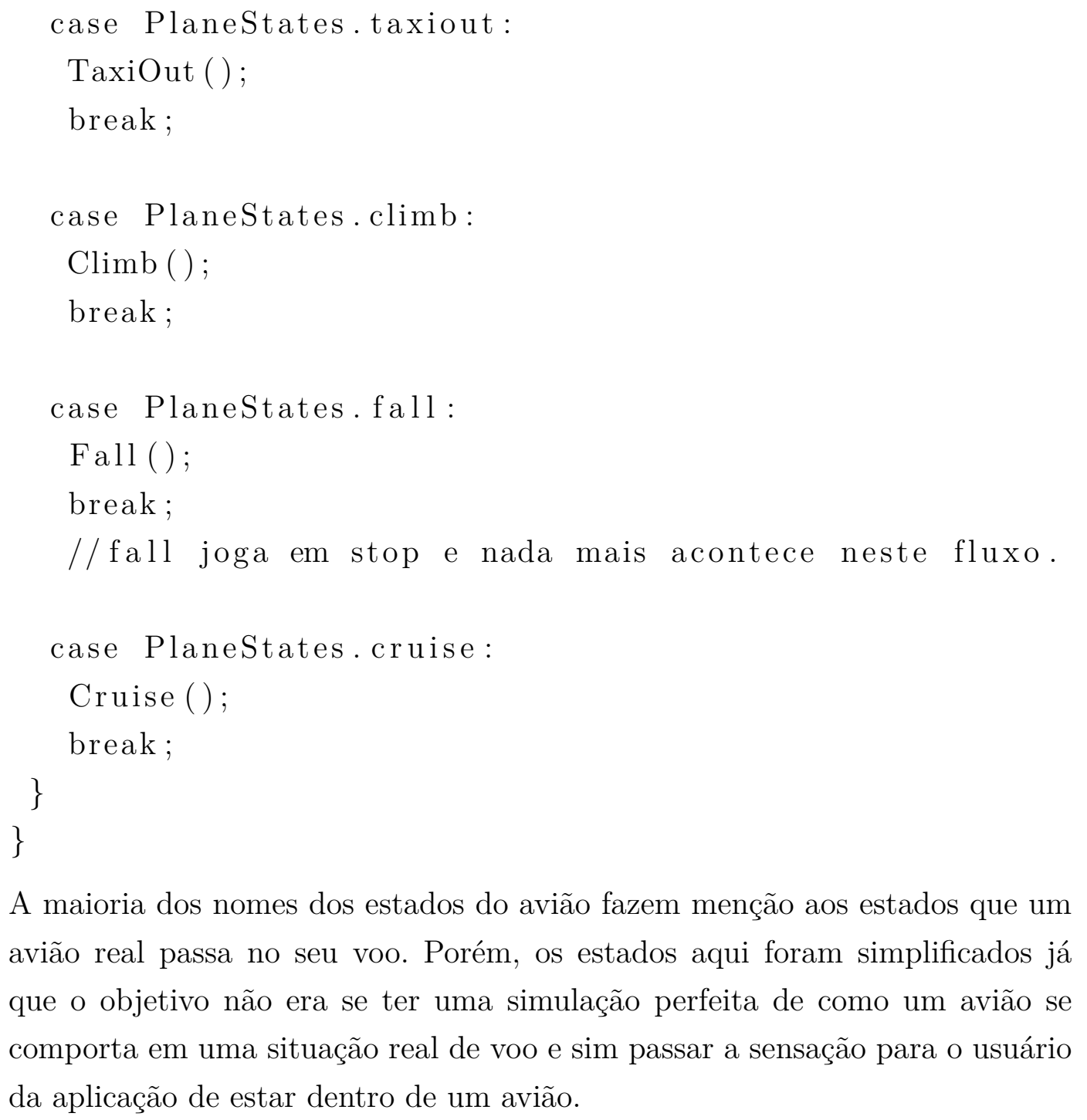

\section{4}

\section{Desenvolvimento da Aplicação Móvel}

A aplicação móvel serve como um controle remoto. Neste controle, o psiquiatra pode afetar o estado atual da aplicação sem ter que interferir diretamente na simulação corrente. Além disso, por ser móvel, é mais fácil de manipular do que uma aplicação separada em outro computador. A aplicação foi desenvolvida para o sistema operacional Android e pode ser executada tanto em tablets como em celulares.

Esta aplicação não tem nenhuma sobrecarga de execução computacional, já que serve para enviar mensagens para a aplicação de RV via wi-fi.

A ideia é que se possa controlar os seguintes aspectos via esta aplicação:

- Turbulência

- Clima 
- Hora atual

- Passagem de tempo

- Nível de estresse

- Quando o pouso ocorrerá

- Bloco de notas

- Aúdio questionando sobre o atual nível de ansiedade

A turbulência, basicamente, é feita com um tremor da câmera atual que pode ter sua intensidade ajustada em 5 níveis diferentes. 0 é sem turbulência e 4 é o máximo de turbulência. O clima foi feito com a ajuda de plugins do Unity, mais especificamente dois deles: O SilverLining(20), que manipula tanto a hora atual quanto o tipo e a quantidade de nuvens presentes na cena, e um simples criador de chuva para fazer as particulas que simulam água caírem.

A passagem de tempo é mais uma configuração do SilverLining. Nesta configuração, é possível fazer com que o tempo dentro da aplicação passe mais rápido ou não passe. Por exemplo, em uma sessão seria ideal ter o horário dentro da simulação na parte da manhã, enquanto em outra, seria interessante que da manhã passasse para a tarde enquanto a simulação estiver executando.

A ideia do nível de estresse é similar a um "nível de dificuldade" de um videogame. Cada nível representa uma dificuldade maior. No caso, os níveis de estresse aqui governam a quantidade de avatares que estarão na aplicação e a quantidade de sons a mais que entram como estimulo. Quanto mais avatares, maior a impressão de se ter um aeroporto mais cheio. Para os sons na aplicação, estes ficam mais altos e o número de pontos de som é aumentado, indicando a presença de mais pessoas no ambiente. O nível 0 indica que não há presença de avatares ou sons a mais enquanto o 5 seria o maior estresse possível.

Após a decolagem, quando o avião já estiver em modo de cruzeiro, é possível começar o processo de pouso em qualquer momento apertando este botão. Assim, o terapeuta fica com controle total deste momento.

O bloco de notas abre uma caixa de texto caso o terapeuta queira fazer anotações rápidas sobre a sessão em andamento. Esse texto então é salvo na aplicação e só será destruído caso o terapeuta delete-o. É ideal para anotações pontuais mas no momento não permite a criação de arquivos separados ou formatações de texto mais complexas.

A ultima opção veio de uma necessidade requisitada pela psiquiatra depois da primeira sessão efetuada com RV. Em diversos momentos da sessão, é necessário saber qual o nível atual da ansiedade do paciente, numa escala de 0 a 10. O botão "Perguntar o nível atual de ansiedade" adiciona um áudio na aplicação de RV que pede para o paciente informar o seu nível de ansiedade 
atual. Isto é feito desta maneira para não quebrar a imersão, já que a aplicação tem diversos áudios que dificultam a comunicação no momento em que eles estão tocando como o barulho das turbinas ou avisos do piloto durante o voo. Na escala, 0 indica "nenhuma ansiedade" enquanto 10 indica "maior ansiedade possível".

A aplicação foi feita dentro do próprio Unity para facilitar a comunicação entre a aplicação móvel e a desktop, já que o Unity tem sua própria implementação de funções de comunicação pela rede. Para fazer a comunicação foi usado o Master Server(21).

O Master Server é um servidor que serve como um ponto de encontro dos clientes que desejam se conectar entre eles. O servidor tem uma única e simples tarefa: Conectar um cliente ao outro.

Ou seja, o servidor é basicamente só um ponto que diz onde e como estão todos os clientes dispostos a conectar. No caso da aplicação de RV, o servidor é tanto servidor como cliente. Esclarecendo melhor: A aplicação de RV, caso seja desejado, pode iniciar uma instância própria do Master Server e já se conectar a ele. Com a aplicação de RV já conectada e o servidor aberto, a aplicação móvel pode entrar no servidor e pedir para se comunicar com a aplicação de RV.

O Master Server pode ser usado de duas maneiras:

- Usando o padrão: O Unity mantém um Master Server sempre online na nuvem.

- Usando um Master Server próprio: A alternativa, que foi escolhida, é manter um Master Server numa máquina local. Neste caso, é a máquina usada para manter a aplicação de RV. O Unity provê arquivos de um projeto em C, e é necessário compilar este projeto para usar. O Master Server é uma simples aplicação de linha de comando.

Ao começar, a aplicação de RV então abre diretamente a aplicação de linha de comando que é o Master Server de fato.

A aplicação móvel então pode enviar um pedido de conexão. Quando o servidor recebe este pedido, ele conecta a aplicação RV como cliente junto com a aplicação móvel, tendo, no fim, uma comunicação peer to peer.

Para efetuar a conexão, dentro do Unity, são necessários alguns atributos:

- O IP do Servidor: O cliente, obviamente precisa tanto do IP quanto da porta em que o servidor está ativo, caso contrário, não conseguirá começar a conexão. Este IP pode ser tanto um endereço na internet quanto um IP na rede local. 
- Nome do Jogo e Tipo de Jogo: O nome e o tipo de jogo são, para este caso, variáveis desnecessárias que servem para identificar as "salas" abertas em um servidor com qual o jogo está sendo jogado e em qual modo. Isto é útil para uma aplicação totalmente voltada a jogos mas no caso aqui é um atributo que é mantido com nomes padrões. O servidor nunca tem mais de uma "sala" aberta e tanto o nome quanto o tipo são constantes.

Os botões executam métodos do tipo Remote Procedure Call(chamada de procedimento remoto) para se comunicarem com o servidor. O RPC é uma chamada para executar uma função e ou método que será executado em outro espaço de endereçamento. Para isso ocorrer, dentro do Unity, é necessário que a função que está sendo chamada remotamente também exista dentro do "cliente" que a está chamando. Por exemplo, na aplicação móvel, ao pressionar um botão, o seguinte método é chamado:

$[\mathrm{RPC}]$

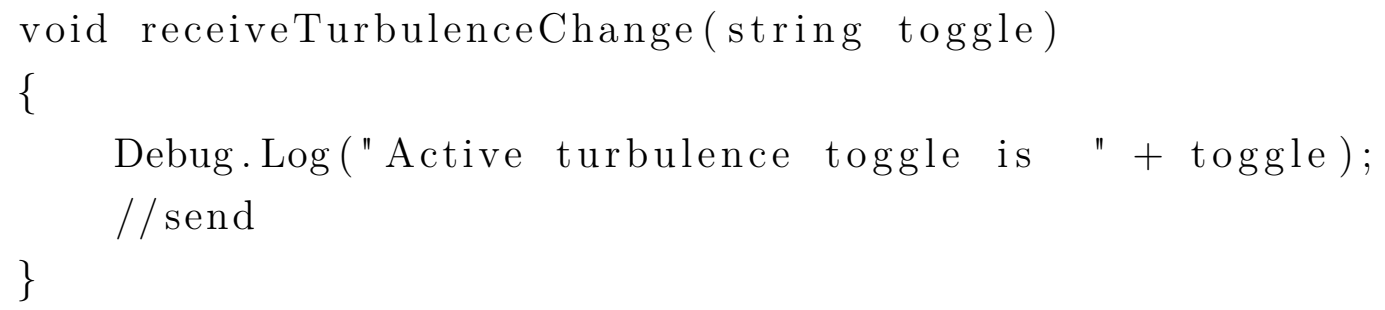

Este método, no cliente, tem antes dele a tag [RPC] que indica que deve existir um método de mesmo nome no servidor. No servidor, portanto, existe um método com o mesmo nome:

$[\mathrm{RPC}]$

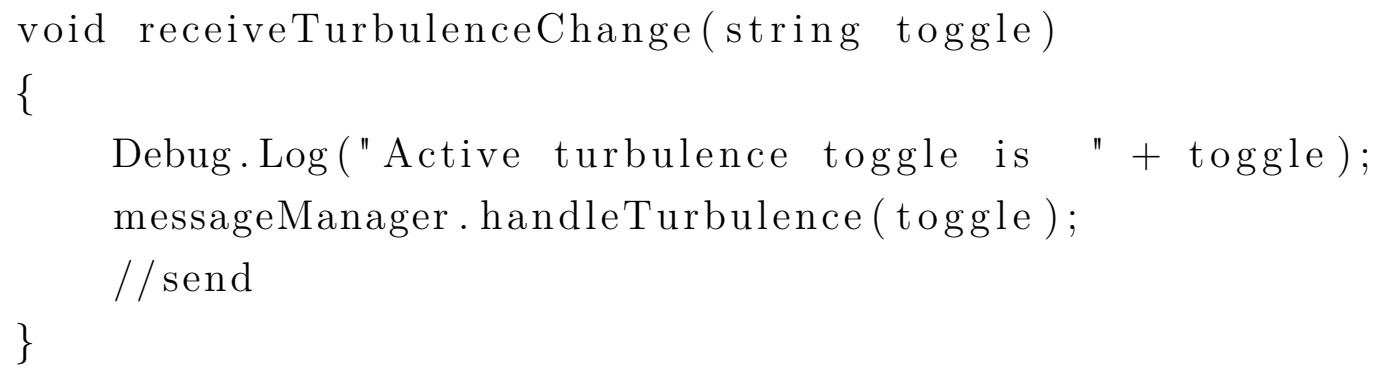

Como é possível notar, o código não precisa ser o mesmo, somente o nome. Portanto, é possível que o cliente e o servidor executem fluxos diferentes, a única similaridade é que eles começam no mesmo ponto. No caso aqui descrito, o cliente não precisa fazer nada, a chamada só é necessária para ativar o método no servidor, onde a mensagem recebida será processada e então acontecerá a mudança necessária no nível de turbulência corrente na aplicação desktop. Não é necessária a criação de nenhuma função de rede, o Unity já tem tudo o que é necessário para acessar os protocolos de rede dentro da engine. 


\section{4 \\ Avaliação}

Para a avaliação da experiência foram conduzidos alguns questionários. Primeiramente foi conduzido o Technology Acceptance Mode Extended(22) (Apêndice B), uma versão estendida do Technology Acceptance Model(23), que avalia a aceitação de uma aplicação dentro de uma organização. Para este questionário, foi decidido usar psiquiatras da própria PUC-Rio para não haver favorecimento. A aplicação foi apresentada para 3 psiquiatras diferentes que usaram a aplicação na posição de pacientes e então eles preencheram os questionários. Este teste foi feito com psiquiatras que não estavam envolvidos com o processo de desenvolvimento da aplicação, para evitar qualquer tipo de viés nas respostas, já que os psiquiatras do IPUB estão envolvidos em todo o processo e portanto tem um certo grau de controle nas características do aplicativo.

O questionário pode ser dividido em quatro grande subcategorias, que tiveram os seguintes retornos dos psiquiatras:

- Intenção de Uso: Demonstra o quão interessado o usuário está no sistema (a aplicação de RV, neste caso). Todos os psiquiatras responderam que tem forte intenções de usar o sistema.

- Usabilidade Reparada: Demonstra o quão útil pode ser o sistema no trabalho do usuário. Aqui no caso, mostra o quão útil o psiquiatra acha que a simulação pode ser no tratamento de fobias. Dois dos psiquiatras marcaram que acreditam que o sistema facilita seu trabalho enquanto um acha que o sistema não trará quase nenhuma facilidade para o seu trabalho.

- Facilidade de Uso Percebia: Indica o quão fácil é de usar o sistema. Todos os psiquiatras indicaram que o sistema é de fácil uso.

- Norma Subjetiva: Indica quanto o sistema é indicado e recomendado por outras pessoas dentro da organização. Como esta foi a primeira vez que estes psiquiatras usaram o sistema, ainda não existe nenhum grande interesse por parte da organização como um todo. 
- Voluntariedade: Indica se o usuário é obrigado a usar o sistema ou usa de forma voluntária. No caso presente, o sistema foi de uso totalmente voluntário e as respostas demonstraram isso.

- Imagem : Indica se o uso do sistema traz algum benefício de reconhecimento ou status dentro da organização. Os psiquiatras concordam no geral que o uso do sistema os faz mais bem vistos na organização, mesmo sendo só neste breve teste.

- Relevância no Trabalho: Demonstra o quão relevante é o sistema no trabalho do psiquiatra. Dois dos psiquiatras acreditam que o sistema é de grande relevância enquanto o último acredita que o sistema não é tão importante mas também não é irrelevante.

- Qualidade do Resultado: Indica quão bom o resultado é. No caso, indica se a aplicação de RV tem uma boa fidelidade de realismo. Todos os psiquiatras acreditam que o sistema traz uma boa sensação de realismo.

- Demonstração de Resultados: Indica como os resultados podem ser entendidos, apresentados para outros e se existe alguma dificuldade em explicar estes resultados para outras pessoas. Todos os psiquiatras acham que os resultados são fáceis de serem entendidos, apresentados e explicados.

O segundo questionário foi o SPES (The Spatial Presence Experience Scale)(24) (Apêndice A). Este é um questionário desenvolvido na área de psicologia para realizar estudos sobre o sentimento de presença espacial de uma pessoa dentro de uma experiência. Embora já existam diversos modelos que avaliem a presença espacial, o SPES foi desenvolvido com o intuito de ser livre e claro o suficiente para poder ser aplicado em diversos tipos de experiências como jogos, realidade virtual e filmes. Assim, o questionário fica mais livre para ser moldado pela necessidade do pesquisador. Para a situação da aplicação desenvolvida, o questionário foi aplicado para a área de realidade virtual.

Como o SPES avalia a experiência da realidade virtual, o questionário foi aplicado a uma paciente que se submeteu ao tratamento em RV. No momento da escrita dessa dissertação, ela foi a única que passou por este processo. O questionário foi feito após a primeira sessão da paciente em RV.

Para o tratamento em RV, o IPUB desenvolveu um protocolo de tratamento (Tabela 4.1) que consiste de oito sessões de tratamento. Porém, este protocolo foi desenvolvido antes da criação da aplicação de RV. Após a criação da aplicação, as sessões eram adaptadas para melhor atender a paciente do 
teste piloto. Para usar em pacientes finais seria necessário reavaliar o protocolo para se ter um cronograma fixo.

A primeira sessão é sem realidade virtual, o paciente é exposto ao que especificamente é a fobia de voar e seus mecanismos além de conhecer a maioria dos efeitos que causam ansiedade. A segunda sessão é um curto treinamento em RV, em que o paciente anda por uma cena neutra, não relacionada com aviões, para se acostumar com ambientes virtuais em geral e seus controles.

A partir da terceira sessão é que começa o tratamento em RV real, no ambiente do avião. Ao passar pela primeira vez pelo tratamento em RV, a paciente demonstrou nervosismo excessivo durante o uso da aplicação. Ao resolver passar da sala de embarque para o avião, a paciente começou a chorar dentro no corredor, no momento que conseguiu ver a aeromoça dentro do avião em seu campo de visão. Por conta disso, a psiquiatra do IPUB que estava presente na sessão decidiu que ela deveria voltar para a sala de embarque (e não entrar no avião, como originalmente previsto no protocolo) e então terminar a experiência para a paciente não ter um ataque de pânico grave.

Em todas as questões do questionário a paciente indicou que concordava fortemente, indicando que estava extremamente imersa no mundo virtual, dando uma constatação que, para ela, a experiência foi extremamente próxima da real. Um grande fator que adicionou ao seu nervosismo foi o fato da paciente ter que fazer uma viagem de avião dois dias após essa sessão.

A quarta sessão foi feita 15 dias depois. A paciente reportou que fez a viagem com a ajuda de diversos remédios que lhe causaram um efeito até de amnésia durante o voo feito. A sessão foi feita um dia depois de ela ter voltado de viagem e, para manter o estado psicológico, ainda estava consumindo um remédio para ansiedade, embora em uma dose bem menor do que a consumida durante a viagem. Nesta sessão a paciente se demonstrou muito mais tranquila e conseguiu fazer o voo até o fim. Porém, sua tranquilidade só se firmou ao saber com certeza que o voo não iria apresentar nenhum tipo de turbulência e seria extremamente tranquilo.

Na quinta sessão a paciente fez um voo com chuva e relâmpagos e mais uma vez se mostrou tranquila, tendo a garantia que não haveria turbulência. A sexta sessão foi efetuada com todos os estímulos: chuva, relâmpagos e turbulência. A paciente ao saber que iria ter turbulência já ficou mais nervosa. Ao ativar a turbulência a sua ansiedade foi máxima mas conseguiu se manter calma o suficiente para terminar a simulação.

Na sétima sessão foi efetuado um voo somente com turbulência que é o ponto que mais afeta a paciente do teste piloto. Mais uma vez ela se demonstrou bastante nervosa com a turbulência. A paciente conseguiu terminar o voo mas 
Tabela 4.1: Descrição de cada sessão no tratamento - Ideia Inicial e Protocolo Executado

\begin{tabular}{|c|c|c|}
\hline Numero da Sessão & Ideia Inicial & Protocolo Executado \\
\hline Sessão 1 & $\begin{array}{l}\text { Explicação da natureza da } \\
\text { ansiedade, o que é a fobia } \\
\text { de avião, os mecanismos que } \\
\text { contribuem para a origem } \\
\text { e manutenção do medo de } \\
\text { voar. }\end{array}$ & $\begin{array}{l}\text { Explicação da natureza da } \\
\text { ansiedade, o que é a fobia } \\
\text { de avião, os mecanismos que } \\
\text { contribuem para a origem } \\
\text { e manutenção do medo de } \\
\text { voar. }\end{array}$ \\
\hline Sessão 2 & $\begin{array}{l}\text { Informações sobre segu- } \\
\text { rança no avião, turbulência } \\
\text { e barulhos. Treinamento } \\
\text { com o uso do Oculus Rift } \\
\text { em uma cena neutra. }\end{array}$ & $\begin{array}{l}\text { Informações sobre segu- } \\
\text { rança no avião, turbulência } \\
\text { e barulhos. Treinamento } \\
\text { com o uso do Oculus Rift } \\
\text { em uma cena neutra. }\end{array}$ \\
\hline Sessão 3 & $\begin{array}{l}\text { Início da terapia de expo- } \\
\text { sição em realidade virtual. } \\
\text { O paciente conhece o aero- } \\
\text { porto, senta no avião mas } \\
\text { não decola. }\end{array}$ & $\begin{array}{l}\text { O paciente conhece o aero- } \\
\text { porto e entra no avião. }\end{array}$ \\
\hline Sessão 4 & $\begin{array}{l}\text { No aeroporto, o paciente se } \\
\text { desloca até o avião e rea- } \\
\text { liza o seu primeiro voo tran- } \\
\text { quilo. }\end{array}$ & $\begin{array}{l}\text { No aeroporto, o paciente se } \\
\text { desloca até o avião e rea- } \\
\text { liza o seu primeiro voo tran- } \\
\text { quilo. }\end{array}$ \\
\hline Sessão 5 & $\begin{array}{l}\text { No aeroporto, o paciente se } \\
\text { desloca até o avião, realiza o } \\
\text { voo tranquilo e anda dentro } \\
\text { do avião para se expor ao } \\
\text { medo de sair do lugar. }\end{array}$ & $\begin{array}{l}\text { O paciente realiza um voo } \\
\text { com chuva e relâmpagos. }\end{array}$ \\
\hline Sessão 6 & $\begin{array}{l}\text { O paciente é submetido a } \\
\text { um voo com chuva. }\end{array}$ & $\begin{array}{l}\text { O paciente realiza um voo } \\
\text { com turbulência. }\end{array}$ \\
\hline Sessão 7 & $\begin{array}{l}\text { O paciente é submetido a } \\
\text { um voo com chuva, relâm- } \\
\text { pagos e turbulência }\end{array}$ & $\begin{array}{l}\text { O paciente realiza um voo } \\
\text { com o estimulo (turbulên- } \\
\text { cia, chuva ou chuva com re- } \\
\text { lâmpagos) que mais o afeta. }\end{array}$ \\
\hline Sessão 8 & $\begin{array}{l}\text { O paciente é submetido a } \\
\text { um voo com chuva, relâm- } \\
\text { pagos e turbulência. Pre- } \\
\text { venção de recaída. Avalia- } \\
\text { ção final. }\end{array}$ & $\begin{array}{l}\text { O paciente é submetido a } \\
\text { um voo com chuva, relâm- } \\
\text { pagos e turbulência. Pre- } \\
\text { venção de recaída. Avalia- } \\
\text { ção final. }\end{array}$ \\
\hline
\end{tabular}


ainda precisa trabalhar sua ansiedade com o efeito de turbulência.

Até o momento do fechamento da versão final desta dissertação ainda faltava realizar uma última sessão que trará uma avaliação final do paciente. Esta sessão provavelmente se passará com todos os estímulos e dará o retorno final da paciente do teste piloto.

Por fim, foi realizada uma entrevista com a psiquiatra responsável no IPUB para determinar o que ela achou do sistema nas duas sessões em que ele foi utilizado. A entrevista foi feita para se ter uma ideia das expectativas da psiquiatra com a aplicação para o futuro e para se ter um retorno do resultado destas duas sessões.

1 O resultado / reação do paciente foi o esperado ao utilizar a aplicação de RV?

- "Sim, o resultado foi o esperado. Podemos perceber oscilações na ansiedade da paciente, de acordo com a cena virtual. O aspecto náusea que estava me preocupando que pudesse ser um limitador importante, a paciente parece já ter melhorado e ter sentido apenas na primeira sessão" (A paciente teve náusea durante a sessão com a cena neutra. Isto é comum na primeira vez que se usa a RV, por isso a cena neutra é de extrema importância) .

2 Essa reação, do ponto de vista do tratamento, foi boa? Ou seja, isso indica que o tratamento pode funcionar, ou o contrário?

- "Sim. Na medida em que o paciente demonstra e relata ansiedade, evidencia que ele teve uma real sensação de imersão, o que é esperado para a eficácia do tratamento com exposição utilizando realidade virtual."

3 Como você compararia essas sessões iniciais com o uso de RV em relação aos tratamentos convencionais, que vocês faziam anteriormente?

- A situação de avião é difícil de fazer as exposições, então a alternativa seria pela imaginação. Muitos pacientes tem dificuldades em imaginar, então a RV facilita bastante.

4 Já dá para criar alguma expectativa (positiva ou negativa) sobre a eficiência desse protocolo de tratamento proposto com o uso de RV para o tratamento da fobia de avião? 
- A expectativa é de que o paciente se sinta imerso na cena virtual e a exposição será eficaz. Entretanto, algumas alterações necessárias que já foram identificadas no atendimento da paciente piloto e através do feedback dela podem adicionar melhora para o aperfeiçoamento do software.

Com estas sessões piloto já foi possível identificar alguns problemas, como por exemplo:

- Os fios do Oculus, fone de ouvido e joystick vão se embolando conforme a paciente gira na cadeira. A cadeira precisa ser girada enquanto se está andando no ambiente virtual já que o controle da aplicação é feito pela rotação do Oculus, representando a cabeça, e um joystick. Este é um problema que vem de como os dispositivos são ligados no momento e é necessário o auxilio de alguém para segurar os fios e ajustar quando necessário.

- A paciente achou difícil sentar na cadeira dentro da aplicação pela sua falta de familiaridade com a aplicação. Isto se deve ao fato de, para não quebrar a imersão, o indicador de qual cadeira sentar ficar bem discreto.

- No momento, todo o voo se passa por um oceano limpo e com céu azul como fundo. A paciente indicou que seria interessante ter terrenos diferentes e poder ver o aeroporto de pouso antes de começar o processo de pouso.

Com relação à evolução da aplicação, a paciente fez algumas sugestões como:

- Aproximar mais a parede do avião ao passageiro já que os assentos são muito espremidos em voos reais e isso causa desconforto em diversos pacientes.

- A paciente do teste piloto,apontou que fica muito com a voz de anúncios que existe no aeroporto do Rio de Janeiro (de onde retiramos as vozes para a aplicação) do que do de Recife (o destino da viagem dela e de onde ela voltou). Então outra ideia para incrementar a aplicação dada por ela seria colocar diferentes vozes para anúncios de voo na sala de embarque, para explorar esta ansiedade que provém de uma voz específica. 


\section{5}

\section{Conclusão e trabalhos futuros}

Neste trabalho foi desenvolvida uma aplicação de RV para tratamento da fobia de voar, com uma aplicação móvel adicional que possibilita dar ao terapeuta a possibilidade de alterar parâmetros do ambiente durante a própria execução do "voo virtual". Isso permite que o terapeuta controle o nível de estresse apresentado ao paciente, trazendo assim para ele uma experiência moldada a sua necessidade no momento. Também foi mostrada a opinião de pessoas que usaram o sistema, para mostrar que realmente existe interesse no sistema.

Com os testes feitos com a paciente do estudo-piloto foi possível ter uma ideia de que a realidade virtual pode ser um substituto para a exposição in vivo. Ao entrar dentro de um aeroporto, mesmo virtual, é capaz de se sentir dentro da situação de estar pronto para pegar um voo. Já com a pesquisa feita com psiquiatras da PUC-Rio, demonstrou-se que existe um grande interesse por parte dos profissionais da área em usar tratamentos de RV em seus pacientes e eles acreditam que a aplicação desenvolvida pode trazer benefícios para pacientes com medos de voar. Além disso, é bom notar que a RV é extremamente mais flexível do que a exposição in vivo: qualquer situação pode ser simulada dentro de um espaço virtual enquanto uma experiência de , por exemplo, turbulência no mundo real dependeria de fatores da natureza que não podem ser controlados.

Para trabalhos futuros, um dos pontos importantes a serem tratados deve ser retrabalhar os cenários e o modelo do avião para que eles consumam menos poder computacional. No momento, a aplicação exige bastante do processador e da placa de vídeo, fazendo com que seu uso em máquinas de desempenho mediano fique comprometido com atrasos de quadros. Além disso, seria ideal adicionar mais opções ao usuário como:

- Representação das mãos no mundo virtual: No momento, o usuário não vê nenhuma parte do seu corpo dentro do mundo virtual. Com um dispositivo Leap Motion preso ao óculos de realidade virtual seria possível fazer uma representação das mãos do usuário no mundo virtual. Isto seria mais interessante especialmente na etapa de voo, onde o usuário 
fica limitado a ficar sentado e girar a cabeça para ver o ambiente ao seu redor.

- Seleção de lugar para sentar: O terapeuta, no futuro, poderia escolher qual o assento o paciente deverá sentar no avião através da aplicação móvel. No momento, a poltrona que o paciente senta é fixa.

- Redução do espaço das cadeiras dentro do avião: O avião que usamos no momento é bem largo, para o paciente ter mais espaço para andar dentro dele. As cadeiras também são bem largas. Mas a paciente do teste piloto reportou que um grande fator que influência na sua ansiedade são as cadeiras pequenas e a sensação de ficar "espremida" próxima a janela. O ideal então seria que o espaço entre as cadeiras e o espaço do corredor fique um pouco menor.

- Limitar movimento da cadeira: No momento, é usada uma cadeira de escritório giratória para poder deixar o paciente posicionar a sua visão da melhor maneira possível durante a sala de espera e o corredor de embarque. Porém, ao sentar no avião o movimento de rotação não faz mais sentido e se o paciente acabar se rotacionando sem querer, a imersão dentro da aplicação de RV será quebrada. O ideal seria ter uma maneira de se travar a rotação da cadeira neste momento de alguma maneira ou então usar uma cadeira feita especialmente para a aplicação.

- Adaptação Afetiva: Os conceitos de adaptação afetiva poderiam fazer com que a aplicação fique mais responsiva ao estado atual do paciente e assim tirar um pouco da sobrecarga do terapeuta responsável pela sessão. Monitorando batidas do coração e alguns padrões cerebrais seria possível fazer com que a aplicação adapte o estado atual dela (trazendo mais ou menos estímulos de ansiedade) de forma automática.

Finalmente, ainda como trabalho futuro, há a necessidade de acompanhar novos testes com pacientes, sejam novos testes pilotos ou testes definitivos com grupos de pacientes, para identificar novos pontos de melhoria da aplicação e, principalmente, pra verificar se a aplicação cumpre seu objetivo final, que é ser eficaz no tratamento do medo de voar (embora entendamos que a análise da eficiência do tratamento em si foge do escopo de uma dissertação da área de informática) 


\section{Referências bibliográficas}

[01] Psiquiatria geral. http://www.psiquiatriageral.com.br/dsm4. Acessado: 2016-03-17.

[02] WeTTERNECK, C.; HART, J.. Potential utility of full motion flight simulators for treatment of individuals with a fear of flying. 2013.

[03] REMOR, E. A.. Tratamento psicológico do medo de viajar de avião a partir do modelo cognitivo: caso clínico, 2000.

[04] EMMELKAMP, P.; KRIJN, M.; HULSBOSCH, A.; DE VRIES; S., S. M. ; VAN DER MAST. Virtual reality treatment versus exposure in vivo: a comparative evaluation in acrophobia. 2001.

[05] Oculus rift. https://www.oculus.com/. Acessado: 2016-03-17.

[06] Sensorama. http://www.medienkunstnetz.de/works/sensorama/. Acessado: 2016-03-17.

[07] IVAN, E. S.. A head-mounted three dimensional display. Fall Joint Computer Conference, 1968.

[09] CARLIN, A.; G., H. H. ; SUZANNE, W.. Virtual reality and tactile augmentation in the treatment of spider phobia: a case report, 1996.

[10] BOTEllA, C.; BAfIOS, R. M.; PERPINA, C.; VILlA, A.; AlCAFIIZ, M. ; REY, A.. Virtual reality treatment of claustrophobia: a case report, 1997.

[11] ROTHBAUM, B.; LARRY, F.; HODGES, L. F.; KOOPER, R.; OPDYKE, D.; WILLIFORD, J. S. ; NORTH, M.. Virtual reality graded exposure in the treatment of acrophobia: A case report, 1995.

[12] BANOS, R.; BOTELLA, C.; PERPINA, C.; MARIANO, A.; LOZANO, J.; OSMA, J. ; GALLARDO, M.. Virtual reality treatment of flying phobia. 2002. 
[13] BRINKMAN, W.; SANDINO, G. ; MAST, V. D.. Field observations of therapists conducting virtual reality exposure treatment for the fear of flying. 2009.

[14] CHITARRO, L.; BUTTUSSI, F. ; ZANGRANDO, N.. Desktop virtual reality for emergency preparedness: User evaluation of an aircraft ditching experience under different fear arousal conditions. 2014.

[15] Game developers, start your unity 3d engines (interview). http://venturebeat.com/2012/11/02/ game-developers-start-your-unity-3d-engines-interview/. Acessado: 2016-03-17.

[16] Página de crowdfunding do oculus. https://www.kickstarter. com/projects/1523379957/oculus-rift-step-into-the-game. Acessado: 2016-03-17.

[17] Vendas do oculus dk2 passam de 100 mil. http://www.theriftarcade.com/ 100000-oculus-rift-dk2s-have-now-been-sold/. Acessado: 2016-0317.

[18] Página de download do fuse na steam. http://store. steampowered.com/app/257400/?1=portuguese.

[19] Fluxo de execução da engine unity 3d. https://docs.unity3d. com/Manual/ExecutionOrder.html.

[20] Silver lining. http://sundog-soft.com/sds/features/ real-time-3d-clouds/. Acessado: 2016-03-17.

[21] Página de referência do master server para unity. http:// unity3d.com/pt/master-server. Acessado: 2016-03-17.

[22] VENKATESH, V.; DAVIS, F. D.. A theoretical extension of the technology acceptance model: Four longitudinal field studies. Management Science 46, 2000.

[23] DAVIS, F. D.. Perceived usefulness, perceived ease of use, and user acceptance of information technology. MIS Quarterly 13, 1989.

[24] HARTMANN, T.; WIRTH, W.; H., S.; KLIMMT, C.; VORDERER, P.; GYSBERS, A.; BOCKING, S.; RAVAJA, N.; LAARNI, J.; SAARI, T.; GOUVEIA, F. ; SACAU, A.. The spatial presence experience scale (spes): A 
short self-report measure for diverse media settings. Jornal Of Media Psychology, 2014.

[25] GARCIA-PALACIOS, A.; BOTELLA, C.; HOFFMAN, H. ; FABREGAT, S.. Comparing acceptance and refusal rates of virtual reality exposure vs. in vivo exposure by patients with specific phobias, 2007.

[26] DA COSTA A., R. T.; SARDINHA ; NARDI, A. E.. Virtual reality exposure in the treatment of fear of flying, 2008.

[27] PRICE, M.; MEHTA, N.; TONE, E. B. ; ANDERSON, P. L.. Does engagement with exposure yield better outcomes? components of presence as a predictor of treatment response for virtual reality exposure therapy for social phobia, 2011.

[28] Gear vr. http://www.samsung.com/global/galaxy/gear-vr/. Acessado: $2016-03-17$. 
A

\section{The Spatial Presence Experience Scale Questionnaire}

The Spatial Presence Experience Scale Questionnaire

Participante número:

Senti que eu estava atualmente dentro do ambiente virtual apresentado

\begin{tabular}{|l|l|l|l|l|l|l|}
\hline Discordo Totalmente & 1 & 2 & 3 & 4 & 5 & Concordo totalmente \\
\hline
\end{tabular}

Pareceu que eu realmente fazia parte do mundo virtual

\begin{tabular}{|l|l|l|l|l|l|l|}
\hline Discordo Totalmente & 1 & 2 & 3 & 4 & 5 & Concordo totalmente \\
\hline
\end{tabular}

Era como se minha verdadeira localização tivesse sido transformada na virtual.

\begin{tabular}{|l|l|l|l|l|l|l|}
\hline Discordo Totalmente & 1 & 2 & 3 & 4 & 5 & Concordo totalmente \\
\hline
\end{tabular}

Eu tive a experiência de que o ambiente virtual me fez visitar um lugar diferente.

\begin{tabular}{|l|l|l|l|l|l|l|}
\hline Discordo Totalmente & 1 & 2 & 3 & 4 & 5 & Concordo totalmente \\
\hline
\end{tabular}

Eu estava convencido que as coisas dentro do mundo virtual estavam realmente acontecendo ao meu redor.

\begin{tabular}{|l|l|l|l|l|l|l|}
\hline Discordo Totalmente & 1 & 2 & 3 & 4 & 5 & Concordo totalmente \\
\hline
\end{tabular}


Eu senti que estava realmente no meio da ação ao invés de estar meramente observando.

\begin{tabular}{|l|l|l|l|l|l|l|}
\hline Discordo Totalmente & 1 & 2 & 3 & 4 & 5 & Concordo totalmente \\
\hline
\end{tabular}

Eu senti que os objetos no mundo virtual estavam ao meu redor.

\begin{tabular}{|l|l|l|l|l|l|l|}
\hline Discordo Totalmente & 1 & 2 & 3 & 4 & 5 & Concordo totalmente \\
\hline
\end{tabular}

Eu senti tanto ambientes abertos quanto fechados como se fossem reais.

\begin{tabular}{|l|l|l|l|l|l|l|}
\hline Discordo Totalmente & 1 & 2 & 3 & 4 & 5 & Concordo totalmente \\
\hline
\end{tabular}

Eu estava convencido que os objetos do mundo virtual estavam localizados ao redor das várias partes do meu corpo.

\begin{tabular}{|l|l|l|l|l|l|l|}
\hline Discordo Totalmente & 1 & 2 & 3 & 4 & 5 & Concordo totalmente \\
\hline
\end{tabular}

Eu tive a impressão que eu podia estar ativo no mundo virtual.

\begin{tabular}{|l|l|l|l|l|l|l|}
\hline Discordo Totalmente & 1 & 2 & 3 & 4 & 5 & Concordo totalmente \\
\hline
\end{tabular}

Eu tive a impressão que eu realmente podia agir no mundo virtual.

\begin{tabular}{|l|l|l|l|l|l|l|}
\hline Discordo Totalmente & 1 & 2 & 3 & 4 & 5 & Concordo totalmente \\
\hline
\end{tabular}

Eu tive a impressão que eu podia alcançar os objetos no mundo virtual.

\begin{tabular}{|l|l|l|l|l|l|l|}
\hline Discordo Totalmente & 1 & 2 & 3 & 4 & 5 & Concordo totalmente \\
\hline
\end{tabular}

Eu senti que eu podia me mover entre os objetos no mundo virtual.

\begin{tabular}{|l|l|l|l|l|l|l|}
\hline Discordo Totalmente & 1 & 2 & 3 & 4 & 5 & Concordo totalmente \\
\hline
\end{tabular}

Eu senti que me envolver totalmente na ação dentro do mundo virtual. 


\begin{tabular}{|l|l|l|l|l|l|l|}
\hline Discordo Totalmente & 1 & 2 & 3 & 4 & 5 & Concordo totalmente \\
\hline
\end{tabular}

O mundo virtual me deu a sensação que eu podia tocar os objetos dentro dele.

\begin{tabular}{|l|l|l|l|l|l|l|}
\hline Discordo Totalmente & 1 & 2 & 3 & 4 & 5 & Concordo totalmente \\
\hline
\end{tabular}

Parecia que eu podia fazer o que quiser no mundo virtual.

\begin{tabular}{|l|l|l|l|l|l|l|}
\hline Discordo Totalmente & 1 & 2 & 3 & 4 & 5 & Concordo totalmente \\
\hline
\end{tabular}

Parecia que eu poderia afetar os objetos no mundo virtual assim como posso na vida real.

\begin{tabular}{|l|l|l|l|l|l|l|}
\hline Discordo Totalmente & 1 & 2 & 3 & 4 & 5 & Concordo totalmente \\
\hline
\end{tabular}

Parecia que eu podia me mover livremente no mundo virtual.

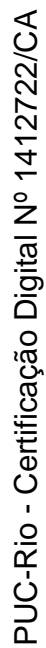

\begin{tabular}{|l|l|l|l|l|l|l|}
\hline Discordo Totalmente & 1 & 2 & 3 & 4 & 5 & Concordo totalmente \\
\hline
\end{tabular}


B

\section{Technology Acceptance Model Extended}

\section{Technology Acceptance Model Extended}

\section{Participante número:}

Intenção de Uso

Supondo que eu tenha acesso ao sistema, eu pretendo usa-lo.

\begin{tabular}{|l|l|l|l|l|l|l|l|l|}
\hline Discordo Totalmente & 1 & 2 & 3 & 4 & 5 & 6 & 7 & Concordo totalmente \\
\hline
\end{tabular}

Dado que eu tenha acesso ao sistema, eu prevejo que o usaria.

\begin{tabular}{|l|l|l|l|l|l|l|l|l|}
\hline Discordo Totalmente & 1 & 2 & 3 & 4 & 5 & 6 & 7 & Concordo totalmente \\
\hline
\end{tabular}

Usabilidade Reparada

O uso do sistema faz com que minha performance no trabalho aumente.

\begin{tabular}{|l|l|l|l|l|l|l|l|l|}
\hline Discordo Totalmente & 1 & 2 & 3 & 4 & 5 & 6 & 7 & Concordo totalmente \\
\hline
\end{tabular}

O uso do sistema aumenta minha produtividade no trabalho.

\begin{tabular}{|l|l|l|l|l|l|l|l|l|}
\hline Discordo Totalmente & 1 & 2 & 3 & 4 & 5 & 6 & 7 & Concordo totalmente \\
\hline
\end{tabular}

Eu acredito que o sistema seja útil no meu trabalho.

\begin{tabular}{|l|l|l|l|l|l|l|l|l|}
\hline Discordo Totalmente & 1 & 2 & 3 & 4 & 5 & 6 & 7 & Concordo totalmente \\
\hline
\end{tabular}

Facilidade de Uso Percebida

Minha interação com o sistema é clara e fácil de compreender.

\begin{tabular}{|l|l|l|l|l|l|l|l|l|}
\hline Discordo Totalmente & 1 & 2 & 3 & 4 & 5 & 6 & 7 & Concordo totalmente \\
\hline
\end{tabular}

Interagir com o sistema não exige muito esforço mental.

\begin{tabular}{|l|l|l|l|l|l|l|l|l|}
\hline Discordo Totalmente & 1 & 2 & 3 & 4 & 5 & 6 & 7 & Concordo totalmente \\
\hline
\end{tabular}

Eu acho o sistema fácil de usar.

\begin{tabular}{|l|l|l|l|l|l|l|l|l|}
\hline Discordo Totalmente & 1 & 2 & 3 & 4 & 5 & 6 & 7 & Concordo totalmente \\
\hline
\end{tabular}


É simples fazer o que eu quero dentro do sistema.

\begin{tabular}{|l|l|l|l|l|l|l|l|l|}
\hline Discordo Totalmente & 1 & 2 & 3 & 4 & 5 & 6 & 7 & Concordo totalmente \\
\hline
\end{tabular}

\section{Norma Subjetiva}

Pessoas que influenciam meu pensamento acham que eu devo usar o sistema.

\begin{tabular}{|l|l|l|l|l|l|l|l|l|}
\hline Discordo Totalmente & 1 & 2 & 3 & 4 & 5 & 6 & 7 & Concordo totalmente \\
\hline
\end{tabular}

Pessoas que são importantes para mim acham que eu devo usar o sistema.

\begin{tabular}{|l|l|l|l|l|l|l|l|l|}
\hline Discordo Totalmente & 1 & 2 & 3 & 4 & 5 & 6 & 7 & Concordo totalmente \\
\hline
\end{tabular}

Voluntariedade

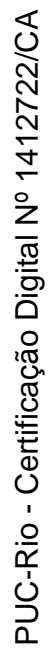

O uso do sistema para mim é voluntário.

\begin{tabular}{|l|l|l|l|l|l|l|l|l|}
\hline Discordo Totalmente & 1 & 2 & 3 & 4 & 5 & 6 & 7 & Concordo totalmente \\
\hline
\end{tabular}

Meu supervisor me obriga a usar o sistema.

\begin{tabular}{|l|l|l|l|l|l|l|l|l|}
\hline Discordo Totalmente & 1 & 2 & 3 & 4 & 5 & 6 & 7 & Concordo totalmente \\
\hline
\end{tabular}

Embora possa ser útil, o uso do sistema não é compulsório no meu trabalho.

\begin{tabular}{|l|l|l|l|l|l|l|l|l|}
\hline Discordo Totalmente & 1 & 2 & 3 & 4 & 5 & 6 & 7 & Concordo totalmente \\
\hline
\end{tabular}

Imagem

Pessoas na minha organização que usam o sistema tem mais prestígio que aquelas que não usam.

\begin{tabular}{|l|l|l|l|l|l|l|l|l|}
\hline Discordo Totalmente & 1 & 2 & 3 & 4 & 5 & 6 & 7 & Concordo totalmente \\
\hline
\end{tabular}

Pessoas na minha organização que usam o sistema são de alto escalão.

\begin{tabular}{|l|l|l|l|l|l|l|l|l|}
\hline Discordo Totalmente & 1 & 2 & 3 & 4 & 5 & 6 & 7 & Concordo totalmente \\
\hline
\end{tabular}

Ter o sistema no meu trabalho é um símbolo de se ter um status maior.

\begin{tabular}{|l|l|l|l|l|l|l|l|l|}
\hline Discordo Totalmente & 1 & 2 & 3 & 4 & 5 & 6 & 7 & Concordo totalmente \\
\hline
\end{tabular}


Relevância no trabalho.

No meu trabalho, o uso do sistema é importante.

\begin{tabular}{|l|l|l|l|l|l|l|l|l|}
\hline Discordo Totalmente & 1 & 2 & 3 & 4 & 5 & 6 & 7 & Concordo totalmente \\
\hline
\end{tabular}

No meu trabalho, o uso do sistema é relevante.

\begin{tabular}{|l|l|l|l|l|l|l|l|l|}
\hline Discordo Totalmente & 1 & 2 & 3 & 4 & 5 & 6 & 7 & Concordo totalmente \\
\hline
\end{tabular}

Qualidade do Resultado.

A qualidade do resultado que tenho do sistema é alta.

\begin{tabular}{|l|l|l|l|l|l|l|l|l|}
\hline Discordo Totalmente & 1 & 2 & 3 & 4 & 5 & 6 & 7 & Concordo totalmente \\
\hline
\end{tabular}

Não tenho problemas com a qualidade do resultado que o sistema produz.

\begin{tabular}{|l|l|l|l|l|l|l|l|l|}
\hline Discordo Totalmente & 1 & 2 & 3 & 4 & 5 & 6 & 7 & Concordo totalmente \\
\hline
\end{tabular}

Demonstração de Resultados

Eu não tenho dificuldades em dizer aos outros os resultados de usar o sistema.

\begin{tabular}{|l|l|l|l|l|l|l|l|l|}
\hline Discordo Totalmente & 1 & 2 & 3 & 4 & 5 & 6 & 7 & Concordo totalmente \\
\hline
\end{tabular}

Eu acredito que possa falar com os outros sobre as consequências do sistema.

\begin{tabular}{|l|l|l|l|l|l|l|l|l|}
\hline Discordo Totalmente & 1 & 2 & 3 & 4 & 5 & 6 & 7 & Concordo totalmente \\
\hline
\end{tabular}

Os resultados do sistemas são aparentes para mim.

\begin{tabular}{|l|l|l|l|l|l|l|l|l|}
\hline Discordo Totalmente & 1 & 2 & 3 & 4 & 5 & 6 & 7 & Concordo totalmente \\
\hline
\end{tabular}

Eu tenho dificuldade em explicar por que o sistema pode ser importante ou não.

\begin{tabular}{|l|l|l|l|l|l|l|l|l|}
\hline Discordo Totalmente & 1 & 2 & 3 & 4 & 5 & 6 & 7 & Concordo totalmente \\
\hline
\end{tabular}

